\title{
THE DETERMINANTS OF HUMAN CAPITAL FORMATION DURING THE EARLY YEARS OF LIFE: THEORY, MEASUREMENT, AND POLICIES
}

\author{
Orazio P. Attanasio \\ University College London \\ and Institute for Fiscal Studies
}

\begin{abstract}
In this paper, I discuss a research agenda on the study of human capital accumulation in the early years, with a particular focus on developing countries. I discuss several methodological issues, from the use of structural models, to the importance of measurement and the development of new measurement tools. I present a conceptual framework that can be used to frame the study of human capital accumulation and view the current challenges and gaps in knowledge within such an organizing structure. I provide an example of the use of such a framework to interpret the evidence on the impacts of an early years intervention based on randomized controlled trial. (JEL: O15)
\end{abstract}

\section{Introduction}

In recent years, a considerable amount of attention has been devoted to human capital accumulation. Scholars have looked at the role of human capital in the process of economic development and stressed the fact that many developing economies that have experienced fast increases in growth have also experienced considerable increases in human capital. Macroeconomists and development economists have been interested in

The editor in charge of this paper was Dirk Krueger.

Acknowledgments: This paper was presented as the Presidential Address at the Meetings of the European Economic Association in Toulouse, August 2014. It draws on my research with a number of co-authors and collaborators: Caridad Arajuo, Sarah Cattan, Flavio Cunha, Emla Fitzimons, Camila Fernandez, Sally Grantham-McGregor, Jena Hamadami, Pamela Jervis, Costas Meghir, Emily Nix, Marta Rubio-Codina, and Marcos Vera-Hernandez. I would like to thank all of them without implying them on the opinions expressed here. I have also learned much from conversations with many people. In particular, I would like to mention Jere Behrman, Raquel Bernal, Pedro Carneiro, Gabriella Conti, Anne Fernald, Lia Fernald, Jim Heckman, Norbert Schady. Finally, special thanks go to Sarah Cattan, Gabriella Conti, Flavio Cunha, Maria Cristina DeNardi, Emla Fitzsimons, Marta Rubio-Codina, and Norbert Schady for reading the first draft of this paper and giving me very valuable suggestions and feedback. The paper has also benefitted from feedback from the Editor and two anonymous referees. My research is partially financed by ESRC professorial fellowship ES/K010700/1 on the accumulation of human capital in developing countries. Attanasio is a Research Associate at NBER, and a Research Fellow at CEPR and BREAD.

E-mail: o.attanasio@ucl.ac.uk

This is an open access article under the terms of the Creative Commons Attribution License, which permits use, distribution and reproduction in any medium, provided the original work is properly cited.

Journal of the European Economic Association December 2015 13(6):949-997

DOI: $10.1111 /$ jeea. 12159

(C) 2015 The Authors. Journal of the European Economic Association published by John Wiley \& Sons Ltd on behalf of European Economic Association 
the relationship between human capital and GDP growth and have proposed models with human capital externalities. ${ }^{1}$ The process of growth and development, at the same time, if associated with the adoption of skill-intensive technologies, will induce an increase in the returns to skills and, therefore, a change in the incentives to accumulate skills. ${ }^{2}$ Moreover, human capital is seen as relevant for distributional issues: crosssectional inequalities in a variety of dimensions (including cognition, health, socioemotional skills) among individuals in many societies seem to emerge very early in life and seem to be strongly linked to inequality of human capital. This is particularly true of certain societies such as Latin America, as discussed, for example, in Lopez and Perry (2008). ${ }^{3}$ One could therefore argue that understanding the process of formation of human capital over the life cycle, and in particular how specific skills that are remunerated by the market develop, is key for the design of policies that want to reduce inequality in the long run.

It is becoming increasingly clear that human capital is a complex object with many different dimensions. Labor markets in different economies reward different skills in different ways, or, in other words, different skills play different roles in the productive process and, as a consequence, have different market prices. In agricultural economies physical strength might be important. Cognitive skills can be more important in industrial and post-industrial economies. Also, socio-emotional skills, such as determination, drive, motivation, sociability, locus of control, and so on, are receiving considerable attention. Changes in technology imply changes in the returns to different dimensions of human capital and changes in the incentives to accumulate certain skills, as in the comparative advantage models used by Pitt et al. (2012) and Rosenzweig and Zhang (2013). Therefore, to assess the economic consequences that different levels of human capital might have on an individual, it is necessary to understand its various components. Of course, different skills (cognition but also self-control, commitment, drive) also have important implications for non-economic outcomes, such as physical and mental health, that are important for individual well-being.

The multidimensionality of human capital is also important to understand the process of its formation, which is a very complex one. A large and growing body of evidence points to the fact that different dimensions (health, cognition, socioemotional development) interact with each other to enhance (or hinder) the productivity of different inputs that affect the accumulation of human capital. The presence of these interactions, which start very early, probably even before birth, together with the fact that past levels of human capital are relevant for its growth in later periods, makes

1. See for instance, Lucas (1988), Romer (1990), Hanushek and Kimko (2000), Hanushek and Woessmann (2008).

2. These processes have wide-ranging implications for the overall return to skills, for the accumulation of human capital and for the evolution of gender differences, if men and women have different comparative advantages in brawn versus skill, as discussed in Pitt et al. (2012) and Rosenzweig and Zhang (2013) who propose versions of the Roy model where individuals select into different occupations depending on their comparative advantage.

3. Recently, some authors have argued that increases in wealth inequality during the last few decades are self-re-enforcing in developed countries (see, in particular, Piketty 2014). 
the entire process dynamic. Processes of this type imply the presence of important complementarities over time and across different inputs that, in turn, imply the presence of salient periods and windows of opportunities.

Yet, the details of these processes are far from being well understood. Interestingly, a similar message can be found in Hackman et al. (2010), which reviews recent contributions in neuroscience that have tried to understand the association between socioeconomic status and brain development. The emphasis there, as here, is in the identification of the mechanisms through which socioeconomic factors can have an impact on human development. On the one hand, there are the biological pathways, which are particularly important in the early years. These may include, for instance, the effect of nutrition or exposure to toxins on brain development in utero or in the first few years, or even the effect that specific parental practices and traits (attachment, stimulation, and so on) might have on development. On the other hand, there are the mechanisms that might give rise to specific forms of investment on the part of parents that eventually generate extremely unequal outcomes. The scope for interactions and synergies among different disciplines, including medicine, neuroscience, psychology, psychiatry, epidemiology, genetics, and economics is obvious.

The early years seem to be extremely important in the whole process, both because events during those years seem to have very long-run consequences and because very young children seem to be very malleable or, conversely, particularly vulnerable to negative environmental factors and different types of shocks. These considerations make the early years particularly salient for policy interventions. Not only might early years interventions be more effective in closing developmental gaps, but they could also make subsequent policies, aimed at, say, school-aged children, more effective. Heckman and his collaborators have been particularly vocal in stressing the importance of the early years.

The fact that early years are important does not mean, however, that everything is determined by (say) age 3 or by some other specific date. Indeed, much recent research shows that there exist other important windows of opportunities, such as, for instance, adolescence (see, for instance, Blakemore and Mills 2014). The early years, however, can be particularly important not only because of the development that is achieved in those years, but because that same development might facilitate and enhance subsequent growth and the productivity of subsequent investments. An interesting research question is whether different ages should be targeted by different interventions and whether specific traits and domain develop more rapidly during certain phases of the child's life cycle.

The importance of the early years and their salience for policy is particularly relevant in developing countries. The Lancet series in 2007 and 2011 (see McGregor et al. 2007; Walker et al. 2011; Engle et al. 2011) have claimed that there are 200 million children at risk of not developing their full potential, and most of these children are in developing countries. These children are particularly vulnerable because of the high incidence and burden of infectious diseases, under-nutrition in the perinatal period and early childhood, micronutrient deficiency, lack of clean water, and limited hygiene, as well as many psychosocial factors, such as violence, lack of stimulation, maternal 
depression, and poor parenting practices. The damage inflicted on these children is likely to be permanent, and delays accumulated in the early years will be difficult if not impossible to fill.

There is overwhelming evidence that socioeconomic disparities are associated with developmental delays and that these delays emerge very early on and grow dramatically during the first few years of life. For instance, Rubio-Codina et al. (2014) show that in Bogotà, Colombia, significant differences in cognitive and language development among children of different socioeconomic backgrounds emerge at around 12 months and grow considerably over time. Paxson and Schady (2007) show that, in Ecuador, the difference in vocabulary at age 6 between children in the fourth decile and children in the first (poorest) decile of the wealth distribution is equivalent to three standard deviations of a $z$-score. This is equivalent to a delay of 2.5 years in language development. These children, who will start attending schools designed for six-yearolds, will not be able to benefit from that experience and will accumulate further delays. Fernald et al. (2012) report similar evidence from India, Indonesia, Perú, and Senegal. While these analyses are based on cross-sectional data, a few studies have used longitudinal data from developing countries. Hamadani et al. (2014), using a longitudinal data set from Bangladesh, show that significant cognitive delays between children of different socioeconomic backgrounds emerge as early as seven months after birth and increase as the children age. By the time they are 64 months, the difference in cognitive development between the poorest and less poor children is as large as 1.2 standard deviations of a $z$-score. This is a remarkable difference as all the households in the study are living in small rural villages and are quite poor. Schady et al. (2015) report evidence based on longitudinal studies from several other developing countries.

The salience of the early years for policy is also confirmed by the growing evidence that well-designed and well-targeted interventions can achieve spectacular results. A number of long-term longitudinal studies that have followed children who received intense and high-quality interventions in the 1960s, 1970s, and 1980s are now available and, in some cases, show strong effects on a variety of adult outcomes. Some of the best known programs, which I discuss in some detail in Section 3, are the High Scope Perry Preschool Project, the Abecedarian, and, in a developing country context, the INCAP nutrition intervention in Guatemala, and the home visits and stimulation intervention in Jamaica.

Of course, given that some of these interventions are intensive and costly, they should be justified by a cost-benefit analysis. However, when, despite its intrinsic difficulties (partly related to the long-term nature of the benefits), this analysis has been performed, the implied internal rates of returns seem extremely high. An example of such an exercise for the Perry Preschool Project is contained in Schweinhart et al. (2005).

Many recent discussions have stressed that the rate of returns on early years is very high, and presumably higher than a number of alternative investments. Heckman et al. (2009) and Heckman (2012), for instance, put the return to the High School Perry Preschool Project at between $6 \%$ and $10 \%$. The existence of such a differential is an 
indication of important frictions that prevent investment in human capital in the early years.

The type of frictions that generate such inefficiencies can be many, ranging from basic credit constraints and imperfections in credit and insurance markets, to information problems and myopic behavior, to the lack of altruism. Imperfections to credit markets can, in turn, be generated by many factors, linked to asymmetric information and difficulties in enforcing contracts on investment whose return is uncertain and is received many years after the initial investment. The fact that returns on human capital are enjoyed by individuals who are different from those who make the investment (children and parents) might also be a problem. Poor parents might also lack the information and sophistication to assess the size of the returns to education. Or, given the stress to which they are subject, they might like the ability of formulating and executing long-term plans that include constant investment of time (stimulation) and resources for their children. In addition to these "efficiency" arguments that can justify policy interventions in human capital, an important justification for interventions targeted to early years is a redistributive one: given the size of the returns of these interventions and their very dynamic nature, they might be extremely effective in reducing inequalities and in fostering "equality of opportunities".

The fact that early years interventions can be effective and the fact that large gaps in development (which are later associated with large differences in earnings, health, and other welfare indicators) emerge very early make these interventions potentially very important. These are policies that have the potential of greatly increasing the efficiency of an economy whilst at the same time reducing the level of inequality and disparities both in economic and other domains. However, not all policies are effective, and the design of policies that are effective at scale, given the available resources (including human resources), is particularly difficult. Having established that interventions to foster the accumulation of human capital in the early years is desirable, the biggest challenge is to develop policies that are scalable in a variety of different contexts and can be implemented with the resources available.

A well-designed and effective policy needs a good understanding of the mechanisms that drive its impacts. This challenge is what motivates the research agenda that I describe in this paper. An understanding of these mechanisms requires a unifying model that frames the main issues. I start my discussion in what follows with the elements of such a framework in Section 2 where I sketch the main components of the framework without specifying its details. The main research questions this framework can address are the following.

1. How does human capital develop in the early years? What are the roles of different types of investment at different points in time? What are the relevant dimensions of human capital and how do they interact in the process of their development among themselves and with different inputs? How large are dynamic complementarities and are there "windows of opportunities" in different dimensions? 
2. How do parent behave? What are the constraints (financial, informational, attitudinal) they face in choosing investment in human capital? How do parents react to interventions?

3. Are policy interventions desirable and what does it take to design an effective policy that can be developed at scale? What aspects of human capital should policies target and when?

As I discuss in Section 3, much has been learned but much is still unknown. The framework I present in Section 2 helps in organizing what we know and what we need to learn. In Section 4, I present a specific example of the conceptual framework, and I exemplify the use of such a framework by discussing a specific intervention and apply the theoretical framework to the analysis of its impacts. I borrow from two recent papers that have performed this analysis. In Section 5, I discuss the role that parental beliefs can play in child development. After that, I discuss two methodological issues: the controversy about the use of a structural model versus an a-theoretical analysis of policy interventions, and the importance of measurement for the entire research agenda. Section 7 concludes with some reflections on future challenges.

\section{A Theoretical Framework}

One first step towards the understanding of the mechanisms behind human capital formation is the construction of a coherent theoretical framework. In this section, I sketch one such a framework and discuss its features. In Section 4, I will then use a particular specification of the framework I present here without details to illustrate a possible use and interpret the evaluation of a specific intervention. The main components of the conceptual framework I consider are: the process of human capital formation and the decision process that determines investment decisions. The latter, in turn, depends on household preferences, information, and resources.

\subsection{The Production Function of Human Capital}

The work on the production function for human capital has a long tradition in economics, going back to the seminal work of Gary Becker (see Becker 1964; Becker and Tomes 1994). More recently, Heckman and his collaborators have greatly advanced the study of human capital formation and proposed a very useful framework (see, for instance, Cunha et al. 2006; Cunha and Heckman 2008; Heckman 2007).

We consider human capital as a multidimensional object that starts evolving very early in life, possibly before birth. I will be calling these different dimensions "factors". One factor could be cognition, another factor could be health and nutritional status, yet another factor could be socio-emotional skills. I will not specify how many factors are relevant and whether a given factor could or should be decomposed into several factors. The different human capital factors change over time according to a process that depends on past levels of the factors and on several environmental variables some 
of which are fixed (such as parental background) and others that are changing over time. Among the latter set of variables, one could distinguish between variables that are chosen by parents or other individuals and/or institutions and others that can be safely considered as exogenous variables. The main difference between the two sets of environmental factors is that the former, which I will call "investments", are chosen by agents who might be reacting to the evolution of the various factors while the latter can be safely considered as having an evolution that is independent of what happens to the various dimensions of human capital.

I will call the process of formation of human capital its production function. Environmental factors and shocks, inputs of various nature, and the existing level of human capital (in its various dimensions) enter the production function in complex and nonlinear ways. Some arguments of the production function could be complements, while other might be substitutes. The presence of lagged values of the factors in the production function makes the process dynamic and, in the presence of complementarities among different arguments, can create windows of opportunities that make investment in certain periods particularly salient and important for future developments. A flexible specification of the production function, when bringing this framework to data, is therefore essential, in order not to preclude the identification of interactions and complementarities.

From the point of view of researchers, some factors are observable, while others are not. The same applies to the environmental factors and investments that enter the production function. The omission of relevant inputs can imply the introduction of important biases in the estimation of the production function. I will discuss briefly these issues in what follows; they are an important area of research.

Investments are chosen by parents, making them endogenous variables in the production function. The endogeneity of investment clearly poses a problem for the empirical identification of the parameters of the production function. If parents react to specific shocks to the child's development that might be unobservable to the researcher, the productivity of investment will be underestimated if parents compensate these shocks, while it will be overestimated if they tend to reinforce them. It is therefore important to model parental behavior and determine whether enough data are available to identify the parameters that inform it as well as the parameters of the production function.

\subsection{Preferences}

In the model I am proposing, parents are assumed to maximize an objective function which depends on their current consumption and on their children's developmental status. Higher development implies higher welfare, as smarter, healthier children are more likely to command higher resources as adults. The dependence of the objective function on child development can be driven by altruism towards the children or by the fact that children can provide support during old age. The fact that parents maximize some sort of objective function does not necessarily mean, as I discuss in what follows, that they make optimal choices. 
One first issue that needs to be addressed is whether the number of children is taken as given or whether fertility choices are also modeled. Of course, the choice between these two modeling alternatives depends on the nature of the problem that one is interested in analyzing. However, if it is assumed that the number of siblings is a variable that enters the production function of the human capital of a given child, it might be necessary to take a stance on this issue. There is an extensive literature on the quantity/quality of tradeoffs in the determination of fertility choices in developing countries that is relevant in this context (see, for instance, Becker and Lewis 1973; Willis 1973; Becker 1991).

In the presence of more than one child, another important issue is the specification of parental preferences across different children. One view could be that parents maximize the total resources their children can command and, therefore, might want to focus investment on the smarter children, if, given the nature of the production function, these are the children for whom such an investment would be most productive. A possible justification of such an assumption is that parents could enforce transfers among siblings to compensate the children who receive the lowest investment. If such transfers are unenforceable or perceived as such by parents, then it is possible that they would try to compensate initial differences among siblings and, possibly, focus their investment on the weakest children. This would be the case if they have a taste for equality among their offspring.

Often in models of parental behavior, households are considered as a unitary decision unit. In reality, households often include more than one adult and these adults might not share the same objectives and tastes. How decisions are made within the households will then be determined by implicit or explicit bargaining processes between fathers and mothers or possibly other adults present, such as grandparents.

\subsection{Resources, Information, and Beliefs}

An obvious constraint parents face is that of resources. The resources parents can access depend on their human capital (the wage they can command on the labor market) and their nonlabor income. The evolution of these variables can depend on a variety of factors, including changes in economy-wide prices and wages and idiosyncratic shocks to productivity. In the presence of uncertainty, parental investment strategies will depend on the ability they have to absorb shocks, which in turn depends on the availability of different smoothing mechanisms, ranging from individual savings, to formal and informal insurance contracts, to credit, to changes in labor supply of various family members.

An important resource that could constitute an important constraint on parental behavior and that is often ignored in the literature is information. Parents make decisions taking as given the production function of human capital. They invest time and material resources in their children as they will expect these investments to have a return in terms of human capital development. How much they will invest will depend, in addition to their tastes and their material resources, on their perception of the production function and, in particular, their beliefs about the productivity of the 
various inputs. Assuming that parents maximize a certain objective function taking as given resources and the production function does not necessarily mean that parents behave optimally. It is possible that they mis-estimate the returns to certain types of investment. Information can, indeed, be an important constraint and a scarce resource. I discuss these issues in Section $6 .{ }^{4}$

This theoretical framework needs to be fleshed out with specific details. The analysis of different problems requires the specification of different details of the model. In Section 5, I use a similar model (with some stark simplification and remorseless omissions) to analyze and interpret the results of a randomized controlled trial (RCT) run to evaluate a policy. This general structure is also useful to organize the various components of a research agenda and to take stock of what we know and what we do not, and the need to learn, for a better understanding of the process of human capital formation and for the design of policies to foster it.

\section{Knowns}

Much has been learned on the importance of the early years and on some of the mechanisms that make these years so salient for human development and for adult outcomes. The evidence that early years events have long-run consequences is extremely strong. Almond and Currie (2011a) present a comprehensive survey of much of the available evidence showing that early events, starting at conception and in the womb, followed by the first few years, have long-lasting impacts on a wide variety of adult outcomes, from schooling, to earnings, to health and others. Researchers have used a variety of ingenious techniques to control for confounding factors to isolate the causal impacts of early shocks. Currie and Hyson (1999), for instance, used the British National Child Development Survey to study the impact of low birth weight on education and employment. Twin studies have been used extensively to control for genetic factors and, more generally, initial conditions that might be correlated with the prevalence of certain shocks. Behrman and Rosenzweig (2004a), for instance, used twins to estimate the return to birth weight. Analogously, many studies have used a variety of natural experiments (such as epidemics) and other methods to isolate the causal impact of early life shocks on subsequent outcomes. Almond (2006), for instance, documents the impacts of the in utero exposure to the 1918 influenza pandemic in the United States. He finds that individuals exposed to the pandemic in utero experienced "reduced educational attainment, increased rates of physical disability, lower income, lower socioeconomic status, and higher transfer payments" (Almond 2006, p. 672).

There is a huge literature that associates child development with socioeconomic factors. Duncan et al. (1994), for instance, stresses the effect that poverty as well as the

4. An interesting angle to this issue has recently been stressed by Mullainathan and Shafir (2013), who argue that poor individuals who live with very scarce resources are constrained in terms of their ability to make forward-looking and optimal choices. 
duration and timing of exposure to poverty can have on children's development. More recently, Hackman et al. (2010) reviewed the approaches taken in neurosciences in this context and stressed the need to understand the causal links and the identification of the processes that lead to the observed associations. The analysis of specific mediating factors (such as parenting practices) can be particularly informative. Hackman et al. argue that useful evidence on these pathways can come from animal studies that can shed light on the biological channels that can be affected by specific practices.

The voluminous literature on human capital development indicates that the early years are important. Nutrition seems to be particularly relevant, especially in the very first phases of human development, before and immediately after birth. Indeed, a large fraction of the 200 million children at risk of not developing their full potential identified in McGregor et al. (2007) are affected by malnutrition. Current estimates identify around 170 million children under five to be stunted, mostly in developing countries and particularly in South Asia and Sub-Saharan Africa (see de Onis et al. 2012).

The nutritional status of pregnant mothers affects in crucial ways the development of the foetus, birth weight, and subsequent development. In epidemiology, Barker's foetal hypothesis, according to which events that affect foetal development during pregnancy (and in particular nutrition) trigger a number of biological effects that have long-run health consequences and may determine chronic conditions, such as high blood pressure and diabetes, has received much attention (see Barker 1995). Economists have more recently paid attention to this hypothesis and have unearthed a substantial amount of evidence on long-run effects of foetal growth on a variety of variables, including test scores, earnings, and educational attainment (see Almond and Currie 2011b).

An impressive study that studied individuals born around the Dutch famine caused by the Nazi embargo in 1944-1945 (see Heijmans et al. 2008) identified epigenetic modifications and, in particular, in the expression of the insulin-like growth factor 2 (IGF2) gene. ${ }^{5}$ The Dutch famine study identified such effects by comparing the genetic material of subjects exposed to the famine while in womb to their siblings born after the famine.

After birth, nutrition in the very early years seems to be important. Some studies ${ }^{6}$ have found association between breastfeeding, early height per age and other indicators of nutritional status in the early years and subsequent outcomes, both in cognitive development and health. Although it is difficult to establish the causal link between breastfeeding and subsequent development, a number of papers have now presented some strong evidence suggesting that breastfeeding causes a number of positive

5. This gene "is a key factor in human growth and development and is maternally imprinted" (Heijmans et al. 2008, p. 17046). Imprinted genes are important since their expression in the present generation depends on the parental environment in which they resided in the previous generation (Jirtle and Skinner 2007).

6. See, for instance, the studies cited in the 2011 Lancet series on Child Development, Walker et al. (2011) and Engle et al. (2011). 
outcomes. Kramer et al. (2001) present evidence from an experiment that evaluated the impact of an intervention aimed at promoting breastfeeding in Belarus, while Fitzsimons and Vera-Hernández (2013) present evidence from the UK Millennium Cohort Study exploiting the different availability of breastfeeding coaching during the weekend to identify the effect of breastfeeding on later outcomes. Both papers show strong impacts of breastfeeding: in the case of the Belarus evidence, breastfeeding reduced infections and other health conditions, while in the case of the UK, the children of mothers with low educations born at the weekend were less likely to be breastfed and, crucially, showed lower indices of child development at ages 3, 5, and 7.

In addition to breastfeeding, nutrition seems to be particularly relevant for child health status and, more generally, for child development. Many papers have shown that stunting in the early years can lead to long-term adverse consequences. In what follows, I discuss the evidence from the influential INCAP intervention in Nicaragua, where children in that study were followed over a period of 40 years. The INCAP study was one of a number of cohort studies in five countries (Brazil, Guatemala, India, the Philippines, and South Africa) that followed children over a period of time, and related both maternal and child nutrition to long-term outcomes. These influential studies, reviewed in Victora et al. (2008), found strong associations between the nutrition status of mothers and children and a variety of outcomes, such as height, schooling, income or assets, offspring birthweight, body-mass index, glucose concentrations, and blood pressure. ${ }^{7}$

Similar associations are also found in a data set from Bangladesh analyzed in Hamadani et al. (2014), which I have already cited. This study, however, while controlling for nutrition and physical growth factors in the first months of life, focuses on the home environment and stimulation. In particular, the study finds a strong association between indicators of home environment as measured at 18 and 60 months and cognitive development at 60 months among poor Bangladeshi children. As already mentioned, socioeconomic variables are strongly associated with cognitive development in that sample. Similar associations are documented in Paxson and Schady (2007) and Rubio-Codina et al. (2014) with data from Ecuador and Colombia, and by Fernald et al. (2012) and Schady et al. (2015) with data from several other developing countries. However, in the Bangladesh study, after controlling for the quality of the home environment, the association is much less strong. Similar results are found in the mediation analysis conducted in Rubio-Codina et al. (2015). This evidence stresses the importance of the home environment and stimulation: these factors seem to be particularly important to explain a large fraction of the variability in children cognitive development and, presumably, adult outcomes.

Along the same lines, Schady (2011) shows that in a longitudinal study of relatively poor children in Ecuador, the unimodal distribution of PPVT (Peabody

7. See Adair et al. (2009), Martorell et al. (2010), Stein et al. (2010), Fall et al. (2011), Kuzawa et al. (2012), and Lundeen et al. (2014). 
Picture Vocabulary Test) scores at age 3 becomes a bimodal distribution by age 5, and that the two modes of the distribution correspond very closely to children of mothers with high and low TVIP (Test de Vocabulario en Imágenes Peabody) scores, respectively. This evidence illustrates powerfully the importance that maternal (and more generally parental) inputs have in the development of children's language and cognitive skills.

The other fact that seems apparent from the literature, is that human capital cannot be considered a monolithic and unidimensional object. Rather, it is a complex construct that is made of many different components. This multidimensionality is important and relevant in two different ways. On the one hand, from an economic point of view, it is clear that different skills command different prices in the labor market, reflecting, probably, the different roles they play in the production process. On the other hand, cognitive skills are certainly important but other skills, which have been called socioemotional or "soft" skills, also play a very important role.

Socio-emotional skills, which include the ability to interact with others, but also to delay gratification, to focus and pay attention, and to be organized, are important for several reasons. First, they might have a direct value in the production process and, therefore, might be remunerated in the labor market. Second, and more subtly, they might facilitate the accumulation of cognitive and other aspects of human capital. $^{8}$ Third, there is some evidence that these skills are malleable over longer time periods, while there is evidence that cognitive skills might become difficult to affect after the first few years. As such, these skills might be particularly salient for policy.

The fact that certain skills developed in the early years might affect the ability to accumulate other dimensions of human capital later is a reflection of the fact that the different domains of human capital follow, over the life cycle of children who enter young adulthood and adulthood, intertwined paths that interact continuously among them and with other inputs in the process of human development. This process is characterized by what the literature defines as "dynamic complementarities" (see, for example, Cunha et al. 2006, 2010). Certain skills, such as socio-emotional skills (see for instance, Duckworth and Seligman 2005), accumulated in the first five years of life, seem to be key to the ability to the accumulation of cognitive skills in subsequent periods. The presence of these interactions and dynamic complementarities might give rise to "key" periods and "windows of opportunities" that could be particularly salient from the point of view of policy design.

\section{Unknowns}

The picture that is emerging from this voluminous and growing literature that spans different fields is therefore one that is starting to make clear several important features of

8. For instance, individuals who can delay gratification might be more likely to lead healthier life styles and, therefore, be healthier. 
the process of human development and of the gaps that are accumulated by vulnerable children. The Lancet 2011 review, for instance, states: "Three translational processes influence how risk factors and stress affect brain and behavioral development: the extent and nature of deficits depend on timing, co-occurring and cumulative influences, and differential reactivity" (Walker et al. 2011, p. 1326).

\subsection{The Mysteries of Human Development}

Yet, many important details are still unknown or extremely vague. These range from the biological mechanisms that affect the process of human development from conception and during the first years of life, to the factors that influence parental decisions and parental practices. For example, the evidence on the impact that micronutrient deficiency during the first years of life may have on child development is still very patchy, as is apparent from the discussion in the recent Lancet series. Despite the fact that many children in developing countries present important deficiencies in many micronutrients, the authors of the series (Walker et al. 2011, p. 1328) conclude that "...[t]here are insufficient data to establish whether supplementation with multiple micronutrients is more effective than iron alone in improving development." Analogously, when discussing infectious diseases, the survey states that "...[e]vidence is insufficient to establish if early parasitic infections affect child development" (Walker et al. 2011, p. 1329). In a similar vein, although the emergence of evidence of epigenetic effects (in animal studies) is fascinating, whether this evidence is of conceptual and practical relevance for the development of human capital is still a contentious issue. Analogously, whether specific genetic configurations mediate the impact of environmental factors is also not completely established, despite some studies pointing to these effects. ${ }^{9}$

Several recent studies have stressed the importance of complementarities among different inputs, which is echoed in the importance of "co-occurring and cumulative influences" mentioned in the previous quote from the Lancet review. The work of Heckman and several co-authors has been particularly forceful in this respect (see, for instance, Cunha et al. 2010). At the same time, the size of these complementarities and the nature of the dynamic relationship between different inputs are still not fully understood. A number of studies now reject the linearity of the production function. ${ }^{10}$ However, we still do not know the details of how the production function of human capital evolves in the early years and how the foundations for further learning are posed.

9. On epigenetics effects see, for instance, Meaney (2010) and Murgatroyd and Spengler (2011), while on the mediation role that certain genetic configurations may have see, among others, Pluess et al. (2013) and Caspi et al. (2010).

10. See Cunha et al. (2006, 2010), Heckman et al. (2013), Cunha and Heckman (2008), and Attanasio et al. (2015a). 


\subsection{Parental Behavior}

In addition to the characterization of the production function for human capital, the other aspect that is key for the design of policies targeted at reducing developmental gaps of vulnerable children, both in developed and developing countries, is the characterization of parental investment and practices. What determines parental choices? What are the constraints that parents face? How do parents react to a specific policy? These are all questions that are key to the successful design of early years interventions. Yet, much still needs to be learned.

Parental decisions are complex, and several factors, such as available resources, mother labor supply possibilities, and beliefs about optimal parental practices, interact to determine them. Parents will invest in children by dedicating time to them and buying toys and books depending on the costs of these investments, how effective they think these activities are, and on the amount of resources they have. They will also consider the tradeoffs between spending time with children, work, and leisure. Moreover, it is likely that parents' choices react to the evolution of the child's development, to possible shocks that might affect children, and to their understanding of how their investments can remediate (in the case of a negative shocks) them.

Finally, parents often have to make decisions to allocate scarce resources among several children, who differ in their age, gender, perceived ability and so on. In his seminal contribution, Griliches (1979) conjectured that parents might tend to alleviate pre-existing differences in abilities. Despite the importance of these issues, not many studies have looked at them (see, for instance, Behrman et al. 1982, 1994a; Becker and Tomes 1976). There are several papers that consider gender biases in investment, which is an important special case of within-household allocation of resources. ${ }^{11}$ Rosenzweig and Wolpin (1988) find some evidence in favor of Griliches' conjecture, while Rosenzweig and Zhang (2009) find that parents in China exhibit higher education expenditure on children with higher birth weight, therefore exhibiting reinforcing behavior. Behrman (1988) finds that parents in South India exhibit some degree of inequality aversion (although they seem to favor boys). In a very recent paper, Yi et al. (2015) consider different dimensions of human capital and find that, in response to early health shocks affecting a sample of twins, parents in China might be pursuing a compensating strategy in terms of health investment and a reinforcing strategy in terms of educational investment. A recent survey (Almond and Mazumder 2013) discusses some of these issues and, in particular, whether parents reinforce or compensate the effect of shocks to the accumulation of human capital or initial conditions. Concluding, they state (Almond and Mazumder 2013, p. 318): “...[w]e expect this area to be a focus of continued research attention because the nature of the behavioral response and its importance to long-term effects are still being debated."

There is a vibrant literature on models of intrahousehold allocations that I cannot summarize here. It is clear, however, that in the presence of two decision makers who

11. See for instance Hazarika (2000), Behrman and Deolalikar (1990), and more recently Jayachandra and Pandi (2015). 
differ in their tastes, it is likely that as a result of changes in their relative bargaining power, allocations could change. Thomas (1990) was one of the first papers to recognize that male and female labor incomes have a different impact on children's development. Economists have looked at many different models of intrahousehold allocations that differ from those that would prevail under a unitary framework. One of the most successful approaches has been that of the so-called collective model proposed by Chiappori $(1988,1992)$. The collective model is attractive because it is agnostic about the specific bargaining process couples engage in and it only assumes that the resulting allocation of resources is efficient. In this context, an important observation about the resources allocated to children is made by Blundell et al. (2005) who note that in the collective model a shift in relative bargaining power in favor of one of the two partners results in an increase in the resources allocated to children only if the marginal propensity to consume on children's goods for that person is higher than that of their partner. That is, it is not the absolute taste for children that determines the effect of a shift in the resources that go to children but the relative marginal propensity to consume. This result has implications for the effect of programs that target specific subsidies to women, such as most recently Conditional Cash Transfers.

Related to the issue of intrahousehold allocation of resources is the more general issue of the role played by the family and the family environment, over and above the resources that different family structures can provide child care givers. In many different contexts, vulnerable children often grow within single adult households. Our understanding of the implications that these different family environments have for child development is still very limited.

\subsection{Interventions and Policies}

In the Introduction, I mentioned a few interventions, both in developed and developing countries, that have been shown, with the help of randomized controlled trials and longitudinal data, to have had large and sustained impacts that have been visible over long periods of time. One of the best known cases is that of the HighScope Perry Preschool Project (PPP), developed in Ypsilanti, Michigan in the mid-1960s: 123 disadvantaged and high-risk children, living near the Perry elementary school in that town, were recruited into a study when aged between 3 and 4 . Of these, 58 (randomly chosen) were assigned to a high-quality preschool program. The study followed them into adulthood. The pattern of results that emerged from that study, which have been analyzed in a number of papers, ${ }^{12}$ is particularly interesting for a variety of reasons. Although the intervention initially boosted cognition (as measured by the Stanford-Binet IQ test), this effect faded a few years later. By age 8, treated boys were indistinguishable, in terms of IQ, from their control counterparts. For girls, the effect of the program on IQ was reduced by remaining statistically different from zero. However, as noted by Heckman et al. (2013), the program's effects on other

12. See Heckman et al. $(2010,2013)$ and the citations therein. 
personality and social skills, such as those measured by "externalizing behavior", remained statistically significant. More importantly, the program seemed to affect academic achievement and, in the long run, a variety of economic outcomes and criminal behavior. One possible interpretation of these results, therefore, is that even when interventions (especially those delivered after age 3$)^{13}$ have a limited impact on IQ, they might affect the long-run welfare of child and adult outcomes through other channels, for instance, through the impact on socio-emotional skills.

Another well-known study is that of the Abecedarian (ABC) project that was developed in the mid-1970s in North Carolina. In that study, 111 disadvantaged children were randomly assigned between a treatment (57) and control (54) group. The program consisted of two stages, one designed for children aged between 0 and 5 and one for children aged between 6 and 8. The first stage was very intense, including play-based adult-child activities to support children's language, motor, cognitive development and socio-emotional competence, including task orientation for up to nine hours each day for 50 weeks/year (see Ramey et al. 1976; Sparling and Lewis 1979). The two stages of the intervention were evaluated with a double randomization design and the first stage has been shown to have a variety of long-run impacts. ${ }^{14}$ Most recently, Campbell et al. (2014) show that ABC had an impact on a variety of health outcomes, including the prevalence of obesity and blood pressure when the subjects were in their mid-30s.

In addition to PPP and the ABC project, many other interventions have been studied in the United States and other developed countries. ${ }^{15}$ Some successful interventions, however, have also been implemented in developing countries. A first program that is worth mentioning is the INCAP study in Guatemala, a nutrition intervention that was evaluated through a randomized controlled trial and whose subjects were followed for over 40 years. Remarkably, even the offspring of the original subjects were observed. The intervention consisted in providing, from 1969 to 1977, a nutritional supplement, rich in calories, in the treatment villages. The children in the control villages were instead provided with a similar beverage, which, however, lacked the additional calories. From 1971, both treatment and control beverages were fortified with micronutrients. As the study went on for several years, children in both treatment and control villages entered the study at different ages: some from birth, some when they were already a few years old. This intervention found impressive long-run impacts. Interestingly, the gains in various dimensions, including adult wages, were significant only for those children that were exposed sufficiently early to the intervention (see, for instance, Hoddinott et al. 2008; Maluccio et al. 2009). Even more impressively, Behrman et al. (2009) find that the program had intergenerational impacts, regardless

13. Interestingly, the previously mentioned nutrition intervention in Guatemala had significant long-run impacts on wages when delivered before the age of 3 .

14. See, for instance, Campbell et al. (2002, 2012). Most of the effects have been documented for the first stage. The second stage did not seem to have detectable effects.

15. Such as, for instance, the Nurse Family Partnership in the United States, which has been evaluated in a number of randomized controlled trials (see, for instance, Olds 2006; Olds et al. 2007, 2010a, b; Eckenrode et al. 2010; Kitzman et al. 2010; Owen-Jones et al. 2013). A similar program, the Family Nurse Partnership, is being evaluated in the United Kingdom (see Owen-Jones et al. 2013). 
of the timing of exposure: the children of the treated girls (but not boys) seemed to be growing faster.

One of the most cited studies, and one that obtained the most spectacular results, is the well-known Jamaica study (Grantham-McGregor et al. 1991; Walker et al. 2005, 2006), which included both a nutrition component (caloric supplementation) and a psycho-social stimulation component. In that study, 129 stunted children in Kingston, Jamaica, were randomly assigned to four groups. In addition to a control group, there was a psycho-social stimulation treatment, a nutrition treatment, and a combination of the two. The intervention targeted children aged between 9 and 24 months at baseline, and lasted for two years. The results were remarkable. At the end of the intervention, both treatments (nutrition and stimulation) seemed to have an impact on cognitive development, and the effect seemed to be cumulative, to the point that the development of children receiving both of them was not very different from that of nonstunted children from the same neighborhoods observed over the same period. After the end of the intervention, the children were observed at ages 7-8, 11-12, and 17-18. Although the effect of the nutrition intervention faded completely, that of the stimulation one was significantly different from zero at all observation points and by sizable amounts. A more recent follow-up (Gertler et al. 2014), at age 22, observed significant effects on earnings, which were increased by $25 \%$, enough for the treated to catch up with the earnings of a nonstunted comparison group.

The few examples I have cited demonstrate that well-designed and well-targeted interventions can yield spectacular results. This is particularly true for early years interventions. Notice, for instance, that while in the case of the PPP the initial impact on the IQ of the treated children fades away a few years after the end of the intervention (although gains in other dimensions, in particular socio-emotional skills, remain significant), in the case of the Jamaica intervention, the IQ impacts remain significant many years after the end of exposure and into adulthood. Such a difference might be explained by the fact that the Jamaica study was targeted at children much younger than those targeted by the PPP. In the case of the ABC project, the IQ impacts also lasted longer. The fact that the $\mathrm{ABC}$, like the Jamaica intervention, also started earlier than PPP is intriguing. However, one should also consider the fact that the ABC was probably more intensive than both PPP and the Jamaica intervention.

Not all interventions, however, are successful, and even successful interventions might have systematically heterogeneous effects, so that some interventions might be more appropriate for certain children while different types of interventions might be more effective for different children. While we are starting to have an idea on which are the elements that generate success, many unknowns still loom large. Open questions include the following. What is the optimal timing of different interventions? What is the optimal duration and intensity of different interventions? What is the best mode of delivery (home visits, center-based care and so on)? What are the key elements in terms of quality that determine success? What dimensions of human capital are better affected by specific interventions at different ages? Should interventions focus on specific dimensions and domains of child development? What is the most appropriate 
curriculum? How important is it that effective interventions in early years are followed by access to high-quality preschools and education?

These unanswered questions resonate even in my brief summary of the impacts of well-known interventions, such as the PPP, the ABC project, and the Jamaica intervention. PPP, which started by and large, past age 3 , seems to have affected socioemotional and "soft" skills in the long run, which in turn seem to have had an impact on other outcomes, ranging from health to economic variables. ABC and, in particular, the Jamaica intervention, instead, seem to have affected cognition and intelligence in a sustainable fashion. Are these differences due to the timing or the content of the intervention? Should the content of intensive interventions be targeted to specific domains? To what extent do the gains in specific domains (such as socio-emotional skills) allow children to exploit better education opportunities? There is still not enough evidence about these issues. Also, these questions, to a large extent, overlap with the main research questions that I have already discussed. How do interventions get their impacts? What is the nature of the production function of human capital? What do parents do and how do they react to interventions? Do interventions crowd parental investment in or out?

Above all, policy makers struggle to build cost-effective and affordable interventions that can be expanded and sustained at scale. Cost is only one aspect of scalability. The availability of appropriate infrastructure, the human resources in the territory, monitoring and supervision schemes that guarantee fidelity and effectiveness of interventions are big issues, especially in developing countries.

A proper understanding of the mechanisms behind human development in the early years, both in terms of the features of the production function for human capital and of the determinants of investment in human capital, is key to the scalability of policies. In addition, to design policies that are effective and that can be deployed on a large scale, it is also key to understand individual behavior and how it reacts to specific interventions.

\section{A Theoretical Framework and its Use}

In this section, I will present a specific example of the theoretical framework I sketched in Section 2 and then use it to interpret the impacts of an intervention evaluated with a randomized control trial. In the process, I will draw on Attanasio et al. (2014a, 2015a).

\subsection{The Model}

In what follows, I will borrow from the model used by Attanasio et al. (2015a), who extend the approach proposed by Cunha et al. (2010). I will use some of the empirical results in this former paper in my discussion in Section 5.2.

I will assume that parents in household $i$ choose investment to maximize utility that depends on their children's human capital and consumption. Their choices are 
made considering a budget constraint and a production function for human capital. At this point I assume that parents have information about the production function of human capital that corresponds to the actual production function. In Section 6, I will explore models in which parents have a distorted view of the production function of human capital. Given what I want to stress and the context to which I will apply this model, I use a static framework. If the focus had been on liquidity constraints and on "crucial windows" in the process of development, it would have been better to formulate the problem as a dynamic one, where parents enjoy utility at different points in time and, possibly, enjoy the returns to human capital investments only much after the investment on human capital was made.

To formalize, let $\boldsymbol{H}_{i, t}$ be the human capital of a child of age $t$ being raised in household $i . \boldsymbol{H}_{i, t}$ is a multidimensional vector, reflecting the different components of human capital, such as cognition and socio-emotional skills and health. The production function of human capital is assumed to depend on the initial level of human capital $\boldsymbol{H}_{i, t}$, on background variables $\boldsymbol{Z}_{i, t}$ (either fixed or time varyingincluding mother $m$, father $f$, and other $r$ ), on investments in human capital $\boldsymbol{X}_{i, t}$ (including materials $M$ and time $T$ ) and on a vector of random shocks $e_{i, t}^{H}$. The "shocks" $e_{i, t}^{H}$ can also be interpreted as reflecting inputs in the production function that are not directly observed or considered by the researcher. ${ }^{16}$ The production function is given by

$$
\boldsymbol{H}_{i, t+1}=g_{t}\left(\boldsymbol{H}_{i, t}, \boldsymbol{X}_{i, t}, \boldsymbol{Z}_{i, t}, e_{i, t}^{H}\right) .
$$

The variables $\boldsymbol{H}_{i, t}, \boldsymbol{Z}_{i, t}, \boldsymbol{X}_{i, t}$, and $e_{i, t}^{H}$ are multidimensional:

$$
\begin{aligned}
\boldsymbol{H}_{i, t} & =\left\{\boldsymbol{\theta}_{i, t}^{c}, \boldsymbol{\theta}_{i, t}^{s}, \boldsymbol{\theta}_{i, t}^{h}\right\} \\
\boldsymbol{Z}_{i, t} & =\left\{\boldsymbol{\theta}_{i, t}^{m}, \boldsymbol{\theta}_{i, t}^{f}, \boldsymbol{\theta}_{i, t}^{r}\right\} \\
\boldsymbol{X}_{i, t} & =\left\{\boldsymbol{\theta}_{i, t}^{M}, \boldsymbol{\theta}_{i, t}^{T}\right\},
\end{aligned}
$$

where I have assumed that, in this particular case, human capital has three dimensions (cognitive skills $c$, socio-emotional skills $s$, and health $h$ ). Most empirical applications I am aware of, partly for data reasons, consider only two dimensions. For instance, Cunha et al. (2010) and Attanasio et al. (2015a) model cognitive and socio-emotional skills, while Attanasio et al. (2014b) model cognitive skills and health. Analogously, the number of "investment factors" and the number of "parental background factors" are somewhat arbitrary. Given the available data and the specific context under study, preliminary factor analysis can be helpful in making the adequate modeling choices.

16. If this interpretation of $e_{i, t}$ is adopted, I will be assuming that these inputs are not chosen by the parents in the problem I consider in what follows. 
Parents are assumed to maximize

$$
\begin{array}{cl}
\max _{\left\{C_{i, t}, \boldsymbol{X}_{i, t}\right\}} & U\left(C_{i, t}, \boldsymbol{H}_{i, t+1}\right) \\
\text { subj. to: } & C_{i, t}+\boldsymbol{P}_{t}^{x} \boldsymbol{X}_{i, t}=Y_{i, t} \\
& \text { and } \boldsymbol{H}_{i, t+1}=g_{t}\left(\boldsymbol{H}_{i, t}, \boldsymbol{X}_{i, t}, \boldsymbol{Z}_{i, t}, e_{i, t}\right),
\end{array}
$$

where $C_{i, t}$ is consumption and $\boldsymbol{P}_{t}^{x}$ is the vector of prices of investments $\boldsymbol{X}_{i, t}$.

The production function $g_{t}$ in equation (1) is assumed to be time varying, so that its parameters or even its shape can be different at different points in time. Notice also that in this simple model there is no saving and only one child. Additional complications and meaningful dynamics could be added to this framework but do not add much to the main message I want to stress.

For the time being, I assume that parents know the production function in equation (1) and take it as a technology constraint to their maximization problem. I will discuss how to relax this assumption in Section 6. Under this assumption, the problem in equation (2) can be solved to derive investment and consumption functions for the parents. Their choices will depend on their tastes, on the parameters of the production function, on prices $\boldsymbol{P}_{t}^{x}$, and on the available resources $Y_{t}^{i}$. The investment functions can be written as

$$
\boldsymbol{X}_{t}^{i}=f_{t}\left(\boldsymbol{H}_{t}^{i}, \boldsymbol{P}_{t}^{i}, \boldsymbol{Z}_{t}^{i}, e_{i, t}^{x}, Y_{t}^{i} ; \boldsymbol{\pi}\right),
$$

where $\pi$ is a vector of parameters that includes those that characterize the utility function and those that characterize the production function, as perceived by the parents. The presence of $\boldsymbol{P}_{t}^{i}$ and $Y_{t}^{i}$ in the investment function, but not in the production function, plays an important role in the identification of the latter, as I discuss in what follows.

This model, while a special case of the framework described in Section 2, is very tightly parameterized and makes some very strong assumptions. It does not consider fertility choices or the quantity/quaility tradeoff in any way; it is silent about intergenerationally transmitted endowments which have been shown to be important to explain certain correlations $;{ }^{17}$ there is limited scope for heterogeneity of parameters and preferences. Most importantly, this structure assumes that all relevant inputs and factors are included and incorporated into the model and that those excluded are completely captured by the term $e_{i, t}^{H}$, which is assumed to be uncorrelated with other factors.

If all the variables in equations (1) and (2), with the exception of the shocks $e_{i, t}^{H}$ and $e_{i, t}^{x}$, were observable, it would be possible to bring this model to the data in a relatively straightforward fashion, by specifying functional forms for the utility function and the production function. In that case, the main problem in estimating the production

17. On the relationship between maternal and child schooling, for instance, see Ashenfelter and Krueger (1994), Behrman et al. (1994b), Behrman and Rosenzweig (2002, 2004b), Rosenzweig and Zhang (2013), and Amin et al. (2014). 
function that determines human capital at age $t+1$ would be the fact that one of the inputs, namely the investment, depends on the shock $e_{i, t}^{H}$. Parents might be reacting to shocks that affect child development in a compensatory or reinforcing way (depending on their preferences, their resources, the nature of the shock, and their beliefs on the technology). To obtain consistent estimates of the parameters of the production function, one would need to take this endogeneity issue into account.

An attractive approach to this problem is to use an instrumental variable or a control function strategy. In either case, identification stems from the availability of variables that affect investment choices and do not enter the production function directly. Prices $\boldsymbol{P}_{t}^{x}$ are particularly attractive in this respect, as it is plausible to assume that households take them as given. Taking the model as written above, one could also use total resources as a source of identification. In this case, however, more caution is needed, especially if resources include earnings, which are obviously related to labor supply choices that, in turn, can indirectly affect the production function through the time inputs. An obvious generalization here would be to include explicitly labor supply choices into the model and to consider alternative uses of parental time. Following this route, then one could think of using wages or labor market conditions as the source of identification. Another important caveat to the use of prices as a source of identification for the role of investment in the production function of human capital is the availability of enough variation. Data from a single time period and a single location might not provide enough variability. However, in some situations one can use geographic variation in prices.

The other major issue to tackle in bringing the model in equations (1) and (2) to the data is the fact that most of its variables are not directly observable. Instead, what researchers usually have is a collection of imprecise measures of the factors that constitute human capital and of the factors that enter its production function. In this respect, the approach proposed by Cunha et al. (2010) is particularly useful. ${ }^{18}$ They explicitly consider a measurement system that relates the factors of interest in the model to the available measures. In particular, they consider the following system:

$$
m_{t}^{k j}=\alpha_{t}^{j k} \theta_{t}^{j}+\varepsilon_{t}^{k j}, \quad j=\{c, s, h, m, f, r, M, T\}, \quad k=\{1,2, \ldots\} .
$$

Here, $m_{t}^{k j}$ is measurement $k$ corresponding to factor $j, \alpha_{t}^{j k}$ are the loading factors that relate factor $j$ at age $t$ to measure $k$ at age $t$, and $\varepsilon_{t}^{k j}$ are measurement errors that make the observable variables $m_{t}^{k j}$ noisy signals of the factors. The way that equation (5) is written implies that each measurement $k$ is affected only by a single factor. This assumption can be somewhat relaxed, but some exclusion restrictions (i.e. some factors excluded from certain measurements) are necessary to achieve identification. I will discuss some of these issues in the application of this model in Section 5.2.

The approach proposed by Cunha et al. (2010) is particularly useful because it considers simultaneously the theoretical framework, with its conceptual issues

18. See Wolfe and Behrman (1984) for an earlier similar approach. 
(including the nature of the production function, the interaction between different inputs, the endogeneity of investment) and the measurement system, with its own set of issues. It also provides good discipline in the use of multiple measures and a good way to summarize the available information within a theoretical coherent fashion. Notice that an important step a researcher implementing this approach has to take is to map measures into factors.

Cunha et al. (2010) use an old theorem by Kotlarski (1967) to establish the nonparametric identification of the joint distribution of the factors and of measurement error. In particular, what is required for the identification of these joint distributions from the empirical distributions of measurement is at least two measurements for each factor and three for at least one. It is also necessary that the measurement error is independent across measures for at least two measures. The intuition of this result is quite clear: to identify the distribution of the factors it is necessary to average out measurement error.

Although the identification is nonparametric, in practice researchers often specify a (flexible) functional form for the joint distributions of the factors and proceed to the estimation accordingly. Once the joint distribution is identified, the estimation of structural relations, such as the production function and the investment function discussed previously, is relatively straightforward. One possible approach, for instance, developed in Attanasio et al. (2014b) and used in Attanasio et al. (2015a), is to take draws from the joint distribution estimated into a first step and use these simulated data to estimate the structural relation of interest by standard techniques (such as nonlinear least squares or nonlinear instrumental variables).

Notice that such relations represent a restriction among the conditional means of several of the factors. As such, they have implications for the joint distribution of the factors one estimates in the first step of the procedure. Normality, for instance, will imply a linear (or possibly log-linear) relationship between the means of the various factors. As such, it would be inconsistent with a nonlinear production function that implies the presence of complementarities between the various inputs. Suppose, for instance, that one wants to allow the production function in equation (1) to be a CES function in which initial conditions, background variables, and investments interact with a certain (finite) elasticity of substitution to generate human capital at age $t+1$. Then the joint distribution of age $t+1$ human capital and the age $t$ human capital and investment factors is necessarily non-Gaussian. It is therefore important, if one does not want to pre-empt answering questions about the nature of the production function, to work with a flexible specification of the joint distribution of the factors. These issues are discussed at length in Attanasio et al. (2014b).

The issue of endogeneity of investment can also be dealt easily within this approach. The instruments considered in the model previously outlined, such as prices $\boldsymbol{P}_{t}^{x}$ and resources $Y_{t}^{i}$, can be added to the measurement system in equation (5) as additional factors (possibly observed without error) and their joint distribution can be estimated. In a second step, then, data for the instruments can be drawn from the joint distribution along with data for the factors and one can apply a nonlinear instrumental variable or a control function approach. Attanasio et al. (2014b, 2015a) use the latter. 


\subsection{Using the Model}

Having set up a framework for the analysis of the accumulation of human capital, I will now show how it can be profitably used in the context of the evaluation of an intervention aimed at fostering the development of young disadvantaged children. I will start with the description of the intervention and its impacts, before moving on to the use of the evaluation data to estimate the production function within the framework laid out in Section 5.

5.2.1. An Intervention and its Impacts. As I mentioned in the Introduction, one of the most successful interventions targeted at vulnerable young children in the early years in developing countries was the Jamaica study I referred to. Although the impact of that intervention was impressive and well documented, it also left some open questions. First, the mechanisms through which the intervention operated are not completely obvious. The comparison of IQ scores between treatment and control children is silent about what generated the impressive impacts that were measured. Second, it is not clear whether such an intervention can be scaled up to a large scale, which would imply the use of local resources and, possibly, a loss in fidelity to the original curriculum. In 2009, in collaboration with Sally Grantham-McGregor and other researchers from UCL and IFS as well as from Colombia, we set up a large randomized controlled trial in Colombia to answer these two questions. Some of the impacts of this intervention, which I discuss in what follows, are reported in Attanasio et al. (2014a).

The Intervention. The first step of the project was the adaptation of the Jamaica curriculum to the Colombian context. This involved not only the translation of the curriculum, but also its cultural adaptation. The Jamaica curriculum is delivered through weekly home visits, roughly one hour long, during which a trained visitor engages in a series of structured activities with the target child and their mother (or main care giver). The activities are designed to be appropriate for the developmental status of the child. They become progressively more complex as the child develops. The activities put much emphasis on language (through language games and a continuous encouragement of the mother to engage the child with language in everyday activities) and cognitive development (through stimulation games, including puzzles and other toys, books and so on). The visits are well structured, in that each visit is described in one page of the curriculum, which specifies what activities are to be performed and the rough order in which they should be performed. The activities are explained in the curriculum in fairly simple and direct language, so as to be accessible to visitors who are not necessarily well educated. The intervention also provides the visitors with some materials (including conversation scenes, books, and toys) and includes teaching mothers how to build a number of toys from recycled materials, such as plastic bottles, wooden blocks etc.

One important innovation relative to the Jamaica study was the use of the infrastructure of an existing welfare program to deliver the intervention. In Colombia, as in many other Latin American countries, there is a large Conditional Cash Transfer 
Program, called Familias en Acción (FeA), which is targeted to the poorest $20 \%$ of the population. Within this program, households receive cash if they comply with certain conditions, which include sending children to school and, in the case of young children, taking them to growth and development checkups in the local health centers. The program also has an important social component, in that beneficiary mothers meet periodically to discuss a variety of issues in what are called Encuentros de Cuidado.

Roughly every 50 or 60 beneficiaries of FeA elect a representative, called Madre Lider (ML), who is in charge of organizing the Encuentros de Cuidado and of the relationship between the beneficiaries and the program officials. Effectively, the ML constitutes the first port of call for any beneficiary that might have a problem with the program. The ML are not paid by the program and perform their activities on a voluntary basis. Such a charge, however, is seen as a prestigious position that confers a status to the ML in the neighborhood.

The MLs, although beneficiaries of FeA themselves, are typically more educated, more entrepreneurial, and, as their title would imply, show more leadership qualities than a typical beneficiary. We therefore had the idea of using them to deliver the intervention. In particular, with the help of the program, in the towns where the study was conducted, we contacted some MLs, trained them, and hired them for the duration of the intervention.

The use of local women, identified through an existing welfare program, is key for the scalability of the intervention that is being investigated. First, obviously, there is the issue of cost. Local women are likely to be cheaper to hire than social workers. Second, we identify women who are likely to be effective in delivering the intervention through the network of a pre-existing welfare program that is very widespread. Such an intervention, therefore, could be replicated throughout Colombia as the program is present in every municipality of the country. Finally, and more subtly, an intervention that aims at changing parental practices and behavior might be more effective if its key messages are delivered and channeled through women in the community. The MLs might be more attuned with, closer to, and more trusted by the mothers, whose behavior the intervention tries to change, than external social workers.

Of course this approach is not without problems. The MLs are typically much less educated than social workers and, therefore, the quality of the intervention could be considerably diluted. The ML's commitment to the intervention might also not be complete. These issues imply that mentoring, monitoring, and supervising might be key to the success of such an intervention. The necessity of mentors, supervisors, and monitors increases the cost of the intervention. Moreover, the intervention itself has to be designed so that it can be delivered by visitors with relatively low level of education and literacy.

The Evaluation. To evaluate the impact of the intervention we designed a cluster randomized controlled trial, and 96 small towns (with populations of between 5,000 and 50,000 inhabitants) were randomly allocated among four groups: (i) a control group; (ii) a stimulation only group; (iii) a nutrition intervention group; and (iv) a nutrition and stimulation intervention group. The nutrition intervention consisted of 
the provision of micronutrients containing iron, folic acid, zinc, and Vitamins A and C. In each town, three MLs were recruited, and children, aged between 12 and 24 months, of beneficiaries represented by those MLs were included in the study. ${ }^{19}$ Among the families represented by each ML, we randomly selected five children in the right age range, so that we ended up with a sample of about 1,440 children at baseline.

The towns we chose were located in the central part of Colombia, covering eight different states. Given our resources we could not cover the entire country and, at the same time, we wanted to have some level of homogeneity across towns, to improve the efficiency of our estimates. However, the area studied is relatively large, roughly three times the size of England. The logistical problems we faced would not be different from those that would be faced by a scaled-up version of the program.

We recruited six professionals who acted as trainers, supervisors, and mentors of the MLs. Each supervisor was assigned 8 of the 48 towns in which stimulation was part of the intervention. These were women with a university degree from medium level universities or a background in child development. Even in this phase, we paid attention to the scalability of the intervention: it should be possible to identify professionals at this level throughout the country. Our supervisors, having been themselves trained for six weeks in Bogotá, trained the MLs in each town for two weeks, after which the intervention started. An additional week of training was provided a month later. After training, the supervisors became monitors and mentors of the MLs. They circuited across the towns, each supervisor visiting each of the towns assigned to her roughly every six weeks. During their stay in a town, they would check on the MLs' activities, accompany them to some home visits, and give them advice. Moreover, they were in constant contact with the MLs through mobile phones and text messages.

Before the intervention started, a baseline survey gathered a considerable amount of information on child development, as well as comprehensive information on the families where they lived. The survey included several tests on children's cognitive, socio-emotional and physical development, including the Bayley scales of Infant and Toddler Development, third edition (Bayley-III), the MacArthurBates Communicative Development Inventories I, II, and III, Spanish-language short forms, and the Infant Characteristics Questionnaire (ICQ, which measures child temperament), and others. We also measured mothers' and children's height weight and haemoglobin levels to assess anaemia. The socioeconomic survey, in addition to a wide variety of household level variables, contained detailed information on the home environment, including several components of the HOME index.

The intervention ran for 18 months. At the end of that period, we collected a followup survey, within which children were assessed again in several dimensions. We also collected information on mothers, home visitors, and, more generally, the household.

19. If in a treatment town a ML did not want to participate into the study, we replaced her with another local woman indicated by her (possibly another ML), but maintained the original children in the study. 
TABLE 1. Impacts of the stimulation and nutrition interventions: standardized treatment effects.

\begin{tabular}{lccc}
\hline & Stimulation & MNP & Stimulation + MNP \\
\hline Bayley III cognition & $0.239^{* * *}$ & 0.029 & $0.227^{* * *}$ \\
& $(0.057)$ & $(0.058)$ & $(0.058)$ \\
Bayley III receptive language & $0.197^{* * *}$ & 0.021 & $0.164^{* * *}$ \\
& $(0.063)$ & $(0.064)$ & $(0.063)$ \\
Bayley III expressive language & 0.025 & 0.056 & 0.077 \\
& $(0.064)$ & $(0.065)$ & $(0.065)$ \\
Bayley III fine motor & $0.089^{*}$ & $0.076^{*}$ & $0.096^{* *}$ \\
& $(0.055)$ & $(0.055)$ & $(0.055)$ \\
Bayley III gross motor & -0.019 & -0.015 & -0.096 \\
& $(0.066)$ & $(0.067)$ & $(0.066)$ \\
MacArthur-Bates-words & $0.108^{*}$ & 0.079 & $0.191^{* * *}$ \\
& $(0.066)$ & $(0.067)$ & $(0.066)$ \\
MacArthur-Bates-phrases & 0.022 & -0.037 & 0.053 \\
& $(0.065)$ & $(0.065)$ & $(0.065)$ \\
Bates-unstoppable & -0.069 & -0.029 & -0.052 \\
Bates-difficult & $(0.077)$ & $(0.077)$ & $(0.077)$ \\
& $-0.147^{* *}$ & -0.007 & -0.088 \\
& $(0.073)$ & $(0.074)$ & $(0.074)$ \\
\hline
\end{tabular}

Notes: Cluster robust standard errors in parentheses. All effects are standardized using the estimated standard deviation of the control group. All estimates control for sex, age (second-order polynomial), tester effect, region effect, baseline level of all test outcomes. Treatment effects estimated on a homogeneous sample of 1,260 children (318 controls, 318 stimulation only, 308 MNP only, 316 stimulation + MNP).

${ }^{*}$ Significant at 10\%; ** significant at 5\%; ${ }^{* *}$ significant at 1\%, using a one-sided hypothesis test (for Bayley and MacArthur-Bates the one-tailed alternative hypothesis $b>0$, for Bates it was $b<0$ ).

Attrition between the baseline and follow-up was not large, as we managed to recontact 1,229 of the original children. Moreover, attrition was not different between the control group and the various treatment arms.

Impacts. The fact that we allocated the 96 towns in our sample randomly to the various types of intervention (stimulation, micronutrient supplementation, and the combination of the two) and the control group allowed us to evaluate the impact of the various interventions in a straightforward fashion, comparing the mean outcomes of the various groups. The presence of a baseline survey allowed us to check the balance among the various samples and also to improve the efficiency of the estimates. Although the number of clusters in the intervention is not huge ( 24 per arm), conditional on baseline observables the intracluster correlation for most outcomes was remarkably low (at around 0.04), making this experiment one of the largest in this area. With the observed intracluster correlation, the 1,267 children are equivalent to a sample of about 880 or 220 per arm. ${ }^{20}$

The main impacts of the intervention are reported in Attanasio et al. (2014a). In Table 1, I reproduce some of the results reported in that paper and describe the

20. The PPP study included 123 children, the Abecedarian 111, and the Jamaica study 129. 
impact of that evaluation. ${ }^{21}$ The stimulation intervention, with or without nutrition, increased cognitive development, as measured by the cognitive scale of the BayleyIII by 0.24 of a standard deviation of the (internally) standardized $z$-score. ${ }^{22}$ The intervention also had an impact of 0.20 on receptive language, as measured by the corresponding scale of the Bayley-III. Finally, we also notice some modest impacts on fine motor skills, which are often considered as a cognitive skill in children of that age.

The main points that should be taken from the table is that the stimulation intervention had a significant impact on cognitive development and on receptive language. The impacts on expressive language are smaller and not statistically significant from zero. There are also some impacts on temperament (which might be an indicator of socio-emotional skills), as measured by the ICQs. There is no significant impact of the nutrition intervention, either on its own or in combination with the stimulation intervention. Remarkably, the nutrition intervention did not have an impact on physical growth and nutritional status, as discussed in Andrew et al. (2014).

One issue is whether the impact found on cognitive development is significant not only from a statistical, but also from a substantive and economic point of view. To interpret the size of the impact, in Figure 1, I report the standardized cognitive scale of the Bayley Scale of Infant Development (BSID) in Bogotá, plotted against age. The two dotted lines refer to the cognitive development of children living in households in the bottom and top quartiles of the wealth distribution in Bogotá. The gap between these two groups is equivalent to about 0.8 of a standard deviation. The thin red line refers to the control group in the RCT. These children are similar to the bottom quartile of the Bogotá sample. The thick blue line is the cognitive development of the children in the treatment group of the intervention. As can be seen, the intervention fills about a third of the gap in cognition between the bottom and top quartiles in Bogotá. If this impact is sustained over time, it is not negligible and its economic benefits in the long run could be substantial. Having said that, it is difficult, given the available evidence, to convert a gain in cognition or some other developmental outcome for a Colombian child into a long-run gain in, say, earnings or academic achievement. These "anchoring" issues are discussed in Cunha et al. (2010).

As a first indication of the mechanism that might have given rise to the impacts we observe in Table 1, in Table 2, we report the impacts that the intervention had on various parental investments (see Attanasio et al. 2013). What is evident from this table is that the stimulation intervention incremented considerably parental investment, as

21. The results are very slightly different from those in Attanasio et al. (2014a) because of small differences in the specification of the regression model.

22. The standardization was performed considering the raw scores for the control group. We first estimated the mean of the $z$-score as a flexible function of age and gender. We then estimated a similar function for the standard deviation and obtained the $z$-score for each of the subscales considered by subtracting from the individual raw score the conditional mean and dividing the result by the estimated standard deviation. We report all the impacts in terms of standard deviation of the these $z$-scores. 


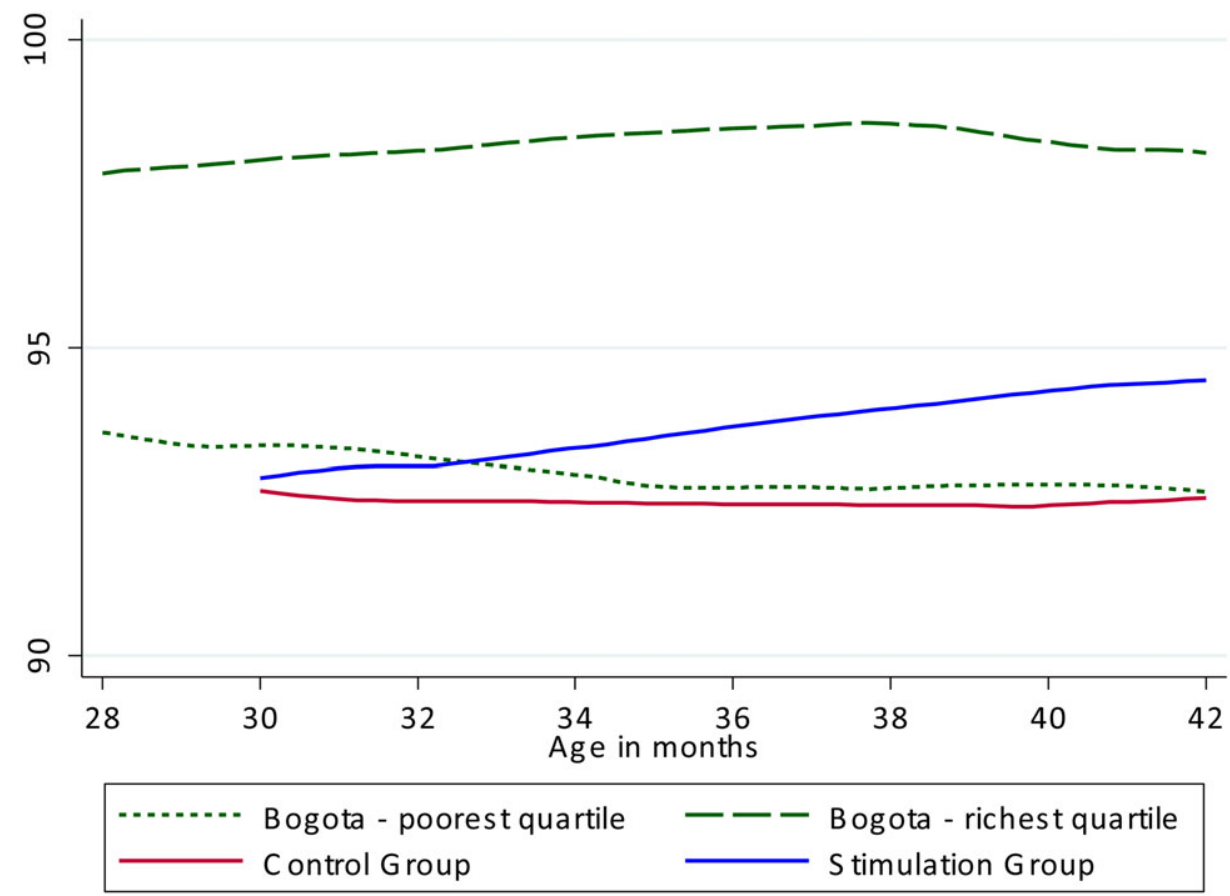

FIGURE 1. Impact on cognitive development relative to Bogotá sample.

TABLE 2. Standardized effects on play investments.

\begin{tabular}{lccc}
\hline & Stimulation & MNP & Stimulation + MNP \\
\hline Number unique play materials & $0.277^{* * *}$ & 0.029 & $0.297^{* * *}$ \\
& $(0.071)$ & $(0.071)$ & $(0.071)$ \\
Number unique play activities & $0.264^{* * *}$ & 0.059 & $0.428^{* * *}$ \\
& $(0.072)$ & $(0.072)$ & $(0.072)$ \\
Proportion with $>$ 4 bought toys & $0.146^{* *}$ & $0.144^{* *}$ & 0.071 \\
& $(0.070)$ & $(0.071)$ & $(0.070)$ \\
Proportion with home-made toys & 0.074 & -0.096 & $0.203^{* * *}$ \\
& $(0.080)$ & $(0.080)$ & $(0.080)$ \\
\hline
\end{tabular}

Notes: Cluster robust standard errors in parentheses. All effects are standardized using the estimated standard deviation of the control group. All estimates control for sex, age (second-order polynomial), tester effect, region effect, baseline level of all test outcomes. Treatment effects estimated on a homogeneous sample of 1,260 children (318 controls, 318 stimulation only, $308 \mathrm{MNP}$ only, 316 stimulation $+\mathrm{MNP}$ ). Number of unique play materials refers to the last seven days. Number of unique play activities refers to the last three days.

${ }^{* *}$ Significant at $5 \% ;{ }^{* *}$ significant at $1 \%$, using a one-sided hypothesis test (for all outcomes the one-tailed alternative hypothesis was $b>0$ ).

measured by several indicators in the data. As I will discuss in what follows, for some reason, parents were convinced to invest more (in time and commodities) in their young children. This evidence constitutes a first hint of the way the impact of the stimulation intervention might have worked. 
5.2.2. Estimating the Model and Interpreting the Impacts. The next step in the study of the intervention that I have been describing, is the estimation of the model discussed in Section 5. Here I will draw on Attanasio et al. (2015a), where my co-authors and I specify two production functions, one for cognitive development and one for socio-emotional skills, and two investment functions.

We let the child outcomes we consider depend on initial conditions, parental investments, parental background variables, and shocks. The specification we use is that of a CES production function:

$$
\begin{aligned}
\theta_{i, t+1}^{j}= & A_{\kappa}^{j}\left[\gamma_{1, \kappa}^{j} \theta_{i, t}^{c \rho_{j}}+\gamma_{2, \kappa}^{j} \theta_{i, t}^{s \rho_{j}}+\gamma_{3, \kappa}^{j} \theta_{i, t}^{m, c \rho_{j}}+\gamma_{4, \kappa}^{j} \theta_{i, t}^{m, s \rho_{j}}\right. \\
& \left.+\gamma_{5, \kappa}^{j} \theta_{i, t+1}^{M} \rho_{j}+\gamma_{6, \kappa}^{j} \theta_{i, t+1}^{T} \rho_{j}\right]^{1 / \rho_{j}} e^{\eta_{i, t}^{j}} \quad j=c, s ; \kappa=d, n .
\end{aligned}
$$

Here, $\theta_{i, t}^{j}$ represents factor $j ;(j=c, s)$ at age $t$ for child $i, \theta_{i, t+1}^{T}$ and $\theta_{i, t+1}^{M}$ are investments in time and materials, respectively, and $\theta_{i, t}^{m, c}$ and $\theta_{i, t}^{m, s}$ are maternal cognitive and socio-emotional skills.

Although such a specification might be considered restrictive, it allows for complementarities between the various inputs, and nests as special cases several interesting cases, such as that of separability (which would occur for $\rho_{j}=1$ ) or that of Cobb-Douglas $\left(\rho_{j}=0\right)$. We also tried other cases, such as a nested CES, which include equation (6) as a special case, and could not reject the restrictions that would yield it.

In equation (6), the term $A^{j}$ represents total factor productivity, while the random variable $\eta_{i, t}^{j}$ represents random shocks that affect the development of skill $j$ at age $t$. The subscript $\kappa$ in equation (6) allows the coefficients of the production function to be a function of the treatment ( $d=$ treatment, $n=$ no-treatment). Finally, we consider two investment factors, $\theta^{M}$ and $\theta^{T}$, the former representing commodities and the latter representing time investment. Both factors are allowed, in principle, to affect both cognitive and socio-emotional skills.

For the two investment factors, we take a linear approximation of equation (4),

$$
\theta_{i, t+1}^{s}=\psi^{s, \kappa} \boldsymbol{W}_{t}+v_{t+1}^{s} ; \quad s=M, T ; \quad \kappa=d, n,
$$

where the vector $\boldsymbol{W}_{t}$ includes all the determinants of investment in equation (4). Notice that we let the parameters of the investment functions $\psi^{s, \kappa}$ depend on the treatment status of the children, to reflect the possibility that the intervention changes the way parents approach the investment problem, as I discuss in what follows. As we allow the intervention, which is assigned randomly, to influence investment, one could argue that the assignment could be a good instrument for taking into account the endogeneity of parental investment in the production function. However, this strategy is precluded if we consider the possibility that the intervention may also affect the production function directly. That is, despite being randomly allocated, the treatment is not a valid instrument as it can enter the production function directly. 
Within this framework, we can see that the intervention can affect child development in three different ways. First, it can change the parameters of the production function, increasing either the productivity of specific inputs or total factor productivity. Second, it can change parental investment, for some reason inducing parents to invest more in their children. Table 2 presents some evidence of this second mechanism. Finally, it is possible that the intervention improves mothers' skills. By estimating the parameters of equation (6) and the distribution of factors, we can test these hypotheses explicitly.

In order to estimate the parameters of equation (6), we follow a two-step procedure, which is discussed extensively in Attanasio et al. (2014b). In particular, we first estimate the joint distribution of the factors and measurement errors. We augment the measurement system in equation (5) to consider also the distribution of the instruments we use, which we estimate jointly with the distribution of factors and measurement errors. Although these distribution are nonparametrically identified, we make some flexible parametric assumption to obtain them more precisely. In particular, we assume that the factors are jointly distributed as a mixture of two log-normal distributions, while the measurement errors are assumed to be jointly log-normal. We perform maximum likelihood estimation, implementing an EM algorithm.

Having estimated distributions for the factors (including the instruments), we draw from it to create a data set and estimate both the investment function and the production function. This is performed by implementing a control function approach and nonlinear GLS on the simulated data. To compute standard errors and confidence intervals, we bootstrap the whole procedure, taking into account the clustered nature of the data (i.e. allowing for correlation within each municipality in the sample).

From this procedure, the importance of using a flexible functional form assumption for the joint distribution of the factors is clear. The production function in equation (6) imposes some restrictions on the conditional means of the various factors (at age $t$ and $t+1)$. In particular, it implies certain nonlinear relations between the mean of the factors at $t+1$ and those at $t$. The nonlinear structure in equation (6) would be inconsistent with, say, joint normality of the factors distribution.

I will not report the tables of estimates of the investment functions and the production functions in Attanasio et al. (2015a). However, the main findings in that paper can be summarized as follows.

1. The production function seems to be well approximated by a Cobb-Douglas production function. The elasticity of substitution between the various inputs considered is not statistically different from 1. Additive separability, instead, is strongly rejected. This is true both for the production function of cognitive skills and that for socio-emotional skills.

2. Initial conditions matter. Initial cognition is a very important determinant of cognition in the second period and initial socio-emotional development is important for subsequent socio-emotional development. Cross-effects are also somewhat important: initial cognition (at ages 12-24 months) is important for socio-emotional development at ages 30-42 months. Initial socio-emotional 
development, however, does not seem to affect subsequent cognition. These last two results contrast with what Cunha et al. (2010) find on a US sample at much older ages. In particular, they find that early socio-emotional development seems to be important for subsequent cognition. It should be stressed that there is not much evidence on this issue for the age group considered here.

3. Parental investments also matter. Investment in "materials" seems to matter for cognitive development, while investment in "time" matters for socio-emotional development. This evidence is also consistent with the mediation analysis in Rubio-Codina et al. (2015) on data from Bogotà, where it is found that play materials seem to be more relevant for cognition and fine motor skills, while time investments relate more to language and socio-emotional development.

4. Parental background has mainly an effect through parental investment. Once we control for investment choices, maternal skills are not very important. Once again, this evidence is consistent with the results on the data from Bogotà in Rubio-Codina et al. (2015).

5. Allowing for endogenous investment is important. The coefficients on investment are estimated to be considerably lower when the production function is estimated by nonlinear least squares ignoring the endogeneity of investment. This finding is important not only for the identification of the marginal product of investment in the production function of human capital but also because the direction of the bias is indicative of the nature of parental investment. A downward bias in the estimates of the coefficients, when endogenous parental reactions are ignored, probably indicates that parents tend to compensate rather than accentuate shocks. ${ }^{23}$

6. The intervention shifts significantly the distribution of the two investment factors considered. Parental investment in time and material is considerably higher in treatment villages than in control ones. This is consistent with the simple mean comparisons reported in Table 2.

7. The parameters of the production function do not seem to be affected by the intervention. This is also true for the total factor productivity. This finding (and the one about investment) is important for interpreting the way in which the intervention obtained the effects reported in Table 1. Rather than making parents (or other factors) more productive, the intervention increased parental investment in child development.

The value of this exercise should be apparent from the list of main findings. First, the estimation of the production function of human capital allows the characterization of the process through which young children develop and the role played by different factors. This is a first step towards filling some of the gaps in our knowledge of such

23. On this point see the discussion in Almond and Mazumder (2013). OLS would yield biased estimates if there is an omitted initial condition that is negatively correlated with the investment or in the presence of measurement error in investment. The factor structure takes the latter into consideration. 
a process. The fact that the nature of dynamic complementarities between different dimensions of human capital is different from what was found, for instance, by Cunha et al. (2010) at different ages, is an indication of the fact that the process of human capital formation is quite complex and we are still far from a full understanding of its features. ${ }^{24}$ Such an understanding is key for the design of policy. The nature and size of dynamic complementarities, for instance, are key to identify crucial periods and windows of opportunities to target interventions. Moreover, if certain dimensions at a certain age turn out to be particularly important, one might want to use interventions that target that specific dimension.

Second, the previously outlined findings give a good idea of the way in which the intervention we have described worked. It seems that, for some reason, the home visits induced parents to invest more, both in terms of money and time, in their children. The next logical step in this research agenda is to understand why parents were not investing "enough" before the intervention.

\section{Beliefs}

A number of interventions seem to have an impact without providing targeted individuals any resources, besides information. Information can have an impact on actual outcomes either because it makes the targeted individuals more productive in getting the outcomes of interest, or because it changes their investment strategies. The intervention in Colombia I have discussed in Section 5.2.1, according to the results in Attanasio et al. (2015a), did not make parents more effective or change the production function. Instead, it increased parental investment. Fitzsimons et al. (2014) discuss an information intervention in Malawi that increased child nutritional status by increasing children's protein consumption (which was in turn financed by an increase in male labor supply).

The questions these results (and others in similar areas) pose are therefore the following. Why was this not happening before the intervention? Why did parents not invest before the intervention in Colombia? Why were parents not working harder to feed their offspring with more proteins before the intervention in Malawi? Several possibilities exist. It is possible that these interventions change parental tastes so as to make them more altruistic towards their children or changing the valuation they give to children outcomes. Or, in the case of the Colombian stimulation program, it is possible that the intervention changed the psychic cost of interacting with the children. An alternative possible answer is that they were not aware of the productivity of their investments. Their choices, as in the model sketched previously, depended on their perception of the production function. If they held a distorted view of the production function and, in particular, underestimated the marginal productivity of

24. Of course there may be many other reasons, in addition to age, behind the difference in results between Cunha et al. (2010) and Attanasio et al. (2015a), such as the different contexts of a developing and developed country. 
parental investment, an intervention that would change that view and move them towards the "correct" one, would increase investment and improve outcomes.

The fact that disadvantaged children are exposed to much less stimulating environments is increasingly documented. ${ }^{25}$ The view that the parents of disadvantaged children seem to underestimate the productivity of investment is consistent with some of the hypotheses discussed by Lareau (2003), who argues that middle-class families, in their parental investment strategies, use what she defines "concerted cultivation", while working class and poor families use parental strategies that rely on "natural growth". Unlike their better-off counterparts, many poor parents do not think children need special inputs, and develop naturally, unless they are affected by severe shocks.

An interesting research agenda, therefore, is to try to estimate parental beliefs on the nature of the production function of human capital. There are several possible approaches to the identification of parental perceptions of the production function. One possibility would be the direct elicitation of such beliefs. This is a good example of the design of innovative measurement tools that I discuss in Section 7.2. Cunha et al. (2013) implement such an approach in an innovative study that looks at the beliefs of pregnant disadvantaged mothers in a hospital in Philadelphia. In Attanasio, Cunha, and Jervis (2015b), we have started the analysis of subjective beliefs elicited in the second follow-up of the children in the Colombian experiment already discussed. Preliminary results indicate that subjective beliefs seem consistent with the idea that parents see investment as productive and necessary especially for children with some problems and delay. This is also consistent with the compensatory nature of parental investment identified in Attanasio et al. (2015a).

Obviously the elicitation of parental beliefs on the production function is not easy. This is a very promising research agenda, but much work is needed on validating different measures and on establishing what is the best way to structure the questions.

An alternative approach to the direct elicitation of beliefs is to try to infer them from investment choices. As I mentioned in Section 5, the parameters of the investment function (4) depend on individual preferences and on individual perception of the production function. To be able to disentangle them, we need to impose some structure on the problem and some variation in the data that allow us to identify taste parameters independently from the parameters of the production functions as perceived by the parents.

In Attanasio and Cattan (2015), we use the idea that an intervention, by providing information (but no resources) to parents, might be changing individual perceptions of the production function. If such an intervention is randomly allocated to different groups of individuals (as is the case, for instance, in the case of the Colombian intervention already mentioned) one can assume that "treated" parents have acquired knowledge of the actual production function and one can use data on child development and parental investment from this group to identify the taste and technology parameters

25. Hart and Risley (1995), for instance, report: "In professional families, children heard an average of 2,153 words per hour, while children in working class families heard an average of 1,251 words per hour and children in welfare-recipient families heard an average of 616 words per hour." 
in equations (1) and (4). Having obtained taste parameters, one can then use investment choices of the "control" parents to identify the parameters of the production function as perceived by these parents and therefore assess the extent to which their beliefs are "distorted".

\section{Research Tools}

In this section, I discuss two methodological issues that are relevant not only for what I have discussed so far, but also at a much more general level. First, I will briefly go over the debate between the proponents of structural models versus those who prefer simpler approaches that make little or no use of economic and behavioral models in analyzing data and, in particular, in evaluating the impacts of social policies. I will then move on to discuss the opportunities afforded by new measurement tools and how they should be constructed.

\subsection{Structural Models and Randomized Controlled Trials}

When looking at data and at what can be learned from correlations, economists are trained to look at behavioral responses that might prevent the inference of a causal relationship among certain variables. Over the last few decades, this set of issues has been taken extremely seriously by most applied researchers in economics. These are, of course, identification issues, which can be addressed either by the availability of exogenous variation (such as that induced by a controlled experiment) or by the imposition of some restrictions that might be derived from economic theory or other knowledge and that can achieve point or set identification.

A part of the profession has taken the view that restrictions derived from theoretical models are essentially arbitrary and that reliable causal evidence can only come from the comparison of means of different samples exogenously exposed to different treatments. Another part of the profession, instead, does not mind imposing restrictions justified by economic theory and possibly functional form assumptions, to achieve identification. The approach taken by the first group is often identified (misleadingly, ${ }^{26}$ in my opinion) as the "reduced form" approach, as opposed to the "structural" approach.

The fact that the profession thinks very carefully about the source of variation in the data that are used to identify certain parameters of interest is an extremely positive development, which distinguishes economists from other social sciences.

26. Misleadingly because a reduced form is derived from a structural model, so that implicitly the economic model should be on the background of any "reduced" form exercise. Analogously, researchers using instrumental variables implicitly assume that the endogenous variable being instrumented is generated by a model that contains the instrument, which in addition has to be excluded from the main relation of interest. 
However, to reduce the empirical analysis to simple comparison of means of different groups in a randomized control trial is, in my opinion, very limitative and narrow. Experiments can be very useful because they introduce variation, which is (if the experiment is constructed carefully), by construction, exogenous. This variation can then be used to estimate behavioral models that are richer and use weaker assumptions than models estimated without the luxury of the experimental variation. Inference from such models is crucial for the design and evaluation of public policies: without a model, it is impossible to extrapolate the results of an experiment to a different context or to estimate the impacts of a slightly different policy in the same context. More importantly, without a model of behavior, it is not possible to understand the mechanisms behind the impacts that one observes in an experiment.

I should also add that the exercise of thinking through the lens of a model of individual behavior or, even better, a model that incorporates general equilibrium effects that take into account the aggregate consequences of a (large) intervention is where the comparative advantage of economists lies in this context. Randomized controlled trials have been around in many sciences for a long time and have also been used in social sciences for a long time. Moreover, there is no reason why economists should be running randomized trials in education, nutrition, child development, or disease control. Many researchers in these disciplines have a much deeper understanding of the specifics of the interventions and of the problems that they try to address. What economists can offer, however, are models of individual behavior that generate the responses that one observes in the data (including, in some situations, general equilibrium effects); specific ways to model the selection and endogeneity issues that affect the working of most interventions in fundamental ways. These models can then be used to extrapolate the results of a specific evaluation to wider contexts.

The work on the ECD intervention I have discussed in Section 5.2 should give an example of the approach I have in mind. In that context, the estimation of the production function for human capital helps to understand how the intervention had its impact. As discussed in Attanasio et al. (2015a), while the experiment can be used to measure the impact of the intervention, further structure is necessary to estimate the production function and, in particular, the role that parental investment plays in explaining child development. In that context, we used variation in prices and family resources (rather than the experiment) to "instrument" investment. This approach allowed us to consider the possibility that the intervention affected directly the production function.

Other examples are available in the literature. For instance, in the context of the conditional cash transfer program PROGRESA, in Mexico, whose impacts have been estimated using a cluster randomized controlled trial, Todd and Wolpin (2006) and Attanasio et al. (2012) used the evaluation data to estimate a structural model of enrolment decisions in school, which they use, amongst other things, to infer the impact of versions of the program with a different grant structure. In the context of India, Duflo et al. (2012) used the data from a randomized controlled trial of an intervention aimed at reducing absenteeism of school teachers by providing a system of incentives to estimate a structural model of labor supply in which effort depends on the nonlinear structure implied by the program. These exercises make a 
profitable use of the experimental variation to understand the mechanisms behind the impacts.

These instances indicate that RCT and structural models are not substitutes, but complements. RCTs allow economists, social scientists, and policy makers to estimate the impact of interventions in a rigorous and, at the same time, simple way. If these experiments are complemented with rich enough data, they can then allow researchers to estimate richer behavioral models that can be used to extrapolate the results of the experiment to different contexts or to slightly different interventions. These models can also be used to interpret the intervention impacts and to understand the mechanisms that generate them. This understanding is useful both to perform welfare analysis and to design better interventions. Finally, the results of the experiment can and should be used to validate and test different models. Data should talk to theory and improve it.

What is central to this discussion is the availability of rich data, that gather information not only on the outcomes of interest but on many environmental variables. These data are necessary to estimate the structural models that can interpret the impacts.

\subsection{Measurement}

Many strong assumptions, which are sometimes made to achieve identification of structural models, are necessary because of the lack of information on certain variables that, while crucial to individual choices, are typically not observed in standard socioeconomic surveys. A good example is that of subjective expectations about future and uncertain variables. In many dynamic models, where uncertainty is relevant, individual agents base their choices on their subjective probability distributions about future events. Expected values of investment returns as well as risk perceptions are bound to be relevant for individual investment decisions. In the absence of direct information on individual perceptions, researchers typically use strong assumptions, such as rational expectations, to model these choices empirically. Even if one is willing to accept rational expectations and consider actual realizations as measurement error-ridden signals of expectations, further and stronger assumptions are needed if one wants to use subjective perceptions of risk, such as variances or standard deviations.

Analogous considerations apply to a variety of other situations, such as individual beliefs on the nature of the returns to certain investments. In the case of the Colombian intervention we have already discussed, parental investment depends clearly on parents' perception of the production function. The standard practice when modeling investment choices is to assume that parents know the form and the parameters of the production function. Yet, as I discuss in what follows, in many situations this is clearly not the case.

One attractive possibility, which has received considerable attention in recent years, is that of the direct elicitation of subjective perceptions, be it of subjective probability distributions or of the return to investments. This approach has a long history. Tom Juster and his colleagues in Michigan played a big role in developing alternative and 
innovative measurement tools. Juster (1966b), cited by Manski (2004), was probably one of the first researchers to try to collect subjective expectations data in a survey. The measurement of subjective expectations is one example, but others exist. Juster (1966a), for instance, studied liquidity constraints in consumption choices by eliciting consumer elasticities in the demand for auto loans to interest rates and maturity. The study cleverly allocated different hypothetical scenarios to randomly chosen groups of consumers.

This type of approach, however, where survey respondents are asked hypothetical questions, has faced much resistance, for a long time, in the economic profession. Economists have refrained from using information elicited through hypothetical questions that do not relate to actual choices individuals make. Economic surveys typically focus on revealed preferences and give no space to subjective answers, or as Manski (2004) puts it, "economists believe what people do, not what they say". The history of this aversion of economists to data not based on choices is briefly discussed by Manski (2004) who, in the context of subjective expectations, strongly advocates the elicitation of subjective probability distributions. In recent years, many studies have shown that this is possible, even in the context of developing countries. ${ }^{27}$

An increasing number of researchers and economists are now systematically going beyond measures based exclusively on choices and "revealed preferences". In my opinion, this is a very desirable development, which goes hand in hand with the development of a variety of measurement tools that are increasingly used in household surveys. These new methods include the elicitation of subjective probability distributions on a variety of outcomes, the elicitation of preferences (such as risk attitudes, patience, present bias, and so on), the elicitation of beliefs on the return to different types of investments (such as school enrolment), the use of experimental games to measure trust, social capital, and so on.

To be sure, the measurement of individual attitudes, beliefs, expectations, tastes, and so on is not easy. Measurement tools can be extremely fragile and subject to a number of issues, such as framing, anchoring, recall biases, as well as many other biases. Economists have much to learn from cognitive psychologists, survey designers, and researchers in other disciplines who have developed many measurement tools that can be adapted and used in economic surveys. Careful piloting and validation of new instruments is necessary. I believe that much can be learned and obtained from clever survey designs and new measurement tools. The economic profession has a strong tradition in developing new successful methods for the measurement of important variables that had been proven difficult to obtain. A good example is the progress made in the measurement of household financial wealth. A few decades ago, it seemed impossible to obtain reliable measures of household financial wealth. The development of new survey methodologies, such as that of the "unfolding brackets" pioneered in the Panel Study of Income Dynamics, have changed that perception considerably. These methodologies have now become standard and are used in many surveys around the

27. See, for instance, the recent survey by Delavande (2014). 
world. One would hope that similar successes can be obtained in developing new measurement tools in a variety of different contexts.

Recent developments in computer power and technology afford a large number of new possibilities in a variety of dimensions. One first and important development is the increasingly common use of administrative data sources, sometimes linked across different data bases and sometimes linked with surveys. Obviously the use of these data poses a large number of delicate problems, concerning privacy and confidentiality. However, their availability constitutes a remarkable opportunity for the progress of social sciences.

Another important development is the use of new technologies to collect accurate data. New data sources collected with new technologies range from scanner data on consumer purchases, which provide extremely fine details on household consumption behavior, to the use of detailed weather data in the study of environmental issues or agriculture, to the integration of new and sophisticated biomarkers (including genetic information) in an increasing number of surveys-such the Health and Retirement Study (HRS), the English Longitudinal Survey of Aging (ELSA), and the Survey of Health, Ageing, and Retirement in Europe (SHARE) - to the use of video technology to obtain information on teacher quality (e.g. the Classroom Assessment Scoring System, CLASS).

7.2.1. Measuring Child Development. In the field of early childhood development, these issues are particularly salient. Measuring the development (physical, cognitive, and socio-emotional) of young children is not easy, especially below the age of 36 months. The best available measures for those age ranges, such as the Bayley's scales of Infant and Toddler Development, third edition (Bayley-III), can be very costly and potentially impossible to use in many countries. In addition to the monetary and time cost ${ }^{28}$ the Bayley-III has to be administered by a qualified psychologist, especially trained in the administration of this test. Moreover, the test has to be administered in standardized settings, so it cannot be done in the child's home. To all this, one has to add the necessity to administer the test in the child's language and, therefore, the necessity to adapt the existing version of the BSID to such a language and cultural context.

A number of shorter and much cheaper tests do exist and are routinely used. These include the Ages and Stages Questionnaire, the Denver Developmental Screening Test, the MacArthur-Bates Communicative Inventories, the Battelle Developmental Inventory, the World Health Organization Motor Milestones, and many others. Many of these tests are based on maternal report and can be administered by a reasonably skilled interviewer rather than a specialized psychologist. The issue, of course, is whether they measure accurately the domains of child development captured by the various scales of the Bayley-III. In a recent study, Araujo et al. (2014) relate the results of the five tests listed above to five subscales of the Bayley-III, where the former were

28. Bayley-III tests on young children can easily take 1.5 hours or more to administer. The cost ranges depending on the context where they are implemented, but it is above US\$120 per child in most countries. 
administered by a survey interviewer and the latter by a trained psychologist. The results are disheartening: the correlations between the "short" tests and the Bayley-III are extremely low, especially at young ages and for children of mothers with low levels of education. In some cases, the correlations are not even significantly different from zero: this is the case for many components of the ASQ tests and the cognition and language scales of the BSID for children younger than 18 months. The ASQ performs badly for cognition even for older children. In general, tests that attempt to measure expressive language perform better, perhaps not surprisingly. For instance, the MacArthur-Bates has a correlation with the expressive language scale of the BayleyIII of around 0.65 for children between 19 and 30 months. In general, all tests perform better (at least in terms of correlation with the Bayley-III) for older children.

Measuring the development of young children in different domains accurately is important both to evaluate the effectiveness of different interventions and to better understand the process of child development. As I mentioned previously, the nature and size of dynamic complementarities between different dimensions of human capital are crucial for policy design: it is necessary to identify the key periods in child development and the role played by specific skills in each period in fostering further development in subsequent stages. Without accurate measures, this is not possible.

Analogous considerations are also relevant for measuring inputs in the process of human capital accumulation. Children are exposed to a variety of environmental stimuli that are likely to play important roles in their development. Modeling and understanding the process of child development and human capital growth in the early years requires good measures of inputs, including parental investments (in time and commodities), school or child care inputs, nutrition, and so on. Measuring the quantity and quality of the inputs in the process of human capital formation is as hard as measuring children outcomes.

Given these issues, it is clear that new measures, possibly exploiting new technologies, might offer important insights. A number of new measures are being developed and studied. Just to mention a few, Neil Marlow and colleagues have developed a new test, PARCA-R (still based on maternal report), which seems to perform better than the ASQ in measuring the development of premature children. ${ }^{29}$ Anne Fernald and her collaborators at Stanford have developed a test (Look-WhileListening, LWL) that uses eye tracking and measure the speed of reaction of children to certain stimuli. They have shown how such a measure changes with age and how it relates to socioeconomic status (see Fernald et al. 2008, 2013). Another interesting instrument to measure the quality of the home environment is the LENA software, which is used to decode day-long recordings to assess the quality of the language environment children are exposed to. ${ }^{30}$ LENA has recently been used together with LWL to analyze pathways of language development in young children by Weisleder and Fernald (2013).

29. See Johnson et al. (2004a,b) and Martin et al. (2012).

30. See Ford et al. (2009). LENA also offers a measure of language development. The software produces a scale that depends on the number and complexity of child vocalization. 
These developments are potentially very important. The development of measures that can be implemented at an affordable cost within large-scale surveys is extremely important for the reasons I have discussed. Much more work is necessary, however, on many of these measures to gain a better understanding of what they are actually measuring. We need to understand which domains of child development they are relevant for, what is their concurrent validity, and what is their predictive power of subsequent outcomes. This is also true for recently developed measures of brain activity. In an interesting recent paper, Lloyd-Fox et al. (2014), for instance, show that near-infrared spectroscopy can be implemented at reasonable costs in very remote locations in Africa. It is not completely clear, however, what aspect of child development the resulting brain imaging measures.

Many of the studies and data sets that I have mentioned so far were developed around the evaluations of interventions that were implemented on a relatively small scale. As a consequence, many of these surveys were not representative at any large scale. It should be clear, however, that large representative surveys are extremely important and that the development of accurate and affordable measurement tools gives the possibility of making them much richer. Over the last few decades we have seen the development of several such surveys, both in developed and in developing countries. Databases such as the Cohort Studies in the UK, the Young Lives initiative, and, more recently, the Encuesta de Primera Infancia in Chile constitute an important tool for research. At the same time, many established large multipurpose surveys (such as the PSID in the United States or ELCA in Colombia) have been including modules with rich measures of child development. These are very positive developments.

7.2.2. Measurement and Theory. New measurement tools, when properly validated, can obviously be very valuable for a variety of purposes. As already hinted, the development of such tools could yield some easily achieved targets. The constriction of new measurement tools, however, is far from trivial and, as I mentioned previously, poses a number of challenges. Moreover, there are some important principles that should drive the construction of new tools.

Which tools are needed should be driven by theory and by the knowledge accumulated from previous empirical studies. In the case of human capital, the theory of child development should define what domains are relevant and should be subject to measurement. More generally, in different contexts, the relevant theory should inform the construction of new measurements. This has been the case in the past. For instance the development of the system of National Accounts was to a large extent induced by the macroeconomic theories that had been developed in previous years and by the necessity to bring those models to data.

As it becomes more common for researchers in economics to be involved in data collection and to have the possibility of influencing the measurements deployed in field surveys, it is also important that the needs of proper econometric approaches inform data collection. For instance, in the case of the factor models I discussed in Section 5.2.2, identification requires at least two measurements for each factor and that the errors associated with each measurement be uncorrelated. Data collection could be 
organized so that such assumptions are likely to be satisfied in the data. In the case of the Colombia study I discussed, some measures of child development (such as the Bayley-III) were collected by a psychologist working with the child, while others, such as the MacArthur-Bates inventories, were collected by an interviewer working with the mother. The assumption that the measurement errors on these different measures (collected on different days by different individuals and based on child observation or maternal report) are independent is probably not very far-fetched.

The other consideration to be made is that the "perfect" measurement probably does not exist. Measurement error is always going to be present to an extent. Moreover, while certainly related to concepts of interest, often available measurements do not coincide with the theoretical concepts that researchers are interested in. In this sense, the factor model in Cunha et al. (2010) is particularly attractive because it makes explicit the presence of measurement error and keeps the theoretical structure and available measures on parallel levels related by the measurement system.

The context of child development and human capital is not the only one in which this is relevant. Models of risk sharing and consumption smoothing typically studied in the literature can be interpreted as factor models where the theoretical framework poses some restrictions on the empirical measures. From a practical point of view, the consideration made by Browning and Crossley (2009), that often it might be worthwhile to invest resources in the collection of two (or more) imperfect measures rather than pursuing the unachievable task of constructing a perfect measure, is certainly relevant (see also Schennach 2004).

\section{Conclusions: A Research Agenda in Child Development}

In this paper, I have discussed a large research agenda that has grown around the recent renewed interest in the accumulation of human capital during the early years. It has become increasingly clear that the early years are extremely important and that what happens to individuals early on has long-lasting consequences. Vulnerable children, living in adverse conditions, accumulate lags that might be difficult to remediate later in life. This mounting body of evidence indicates that the early years might be particularly salient for policy interventions, as strongly argued by Heckman (2008). Much work is still needed, however.

In Section 4, I have suggested already what I think are the main challenges for current research on early child development and the accumulation of human capital. It might be however useful to summarize them here. Again, the theoretical framework, whose component I sketched in Section 2, is useful to organize this discussion. The two big components of such a research agenda are, in my opinion, the characterization of the production function of human capital and the characterization of parental behavior.

Our understanding of the production function of human capital in the early years is still very incomplete. Human capital is now understood as a multidimensional object, where different domains, ranging from physical growth to cognition and language, to socio-emotional skills, develop in a intertwined fashion over time. The nature of 
these dynamic interactions is still not completely understood. We need to quantify the complementarities between different components of human capital and the various inputs that enter the production function and, crucially, how these complementarities change over the life course, as children develop. Parental investment (and the inputs from child care or schools) have different dimensions and these different dimensions can affect different components of human capital differently. The pathways through which these investments manifest into developmental outcomes need to be fully characterized. This evidence is key for the design of effective policies, as they are key for the identification of windows of opportunities and for the identification of specific domains that should be targeted in specific periods by specific forms of investment.

From a methodological point of view, a systematic use of flexible latent factor models can be useful. An explicit treatment of measurement error and the recognition that complete measurement of all relevant factors and inputs can be extremely difficult, if not impossible, is important. An analysis of the biases that can be introduced by ignoring certain domains of human capital or certain types of investment would be very useful. Many of the available studies make some very strong assumptions on the dynamics of human capital. For instance, all the studies I am aware of assume a Markov structure, so that the current level of development is a sufficient statistics for the effect of past levels of human capital in the production function. It would be important, in particular for the identification of key stages, to check whether such an assumption is a realistic one or whether it is violated in practice. Or, for tractability, it is often assumed that the relevant periods in the development of human capital coincide with those for which developmental outcomes are available. Data sets containing good quality data for a long period and with a sufficiently high frequency could be used to investigate how robust inferences are when some of these assumptions are violated. Furthermore, additional theoretical and empirical research is needed to establish what types of biases are introduced in the study of the production function from the omission of important factors that might be unobserved in many data sets.

Parental investment, which is crucial in shaping child development, depends on parents' objectives, on their resources, and on their beliefs about the nature of the production function. Yet, we have only a partial understanding of each of these components. Much work is needed in studying parental tastes and objectives, especially when considering the allocation of resources among several siblings of different gender and possibly ability. Also, as already discussed, gender issues can also be relevant as mothers and fathers might differ in their preferences and in their attitudes towards children. We also have a limited understanding of and information about parental investment. Parents can do many different activities to foster their children's development, which range from spending time with them on different activities, to buying toys and books, to contracting services, such as private lessons etc. Different inputs might be targeted at different domains of human capital. Better information on these items is needed to model parental behavior empirically. Finally, parental choices will crucially depend on parental beliefs about the production function. A better understanding of these issues is, in my opinion, key in characterization of parental investments in children. 
A number of interventions, both in developed and developing countries, have proven to be effective in achieving sustainable impacts that, in some cases, have had large long-run effects on adult outcomes. However, the mechanisms through which these interventions work are not fully understood. Moreover, the biggest challenge probably lies in designing affordable interventions that are effective at scale.

In order to tackle these outstanding issues, research needs to combine a variety of methods. I have argued for the development of new measurement tools, which seem particularly important in this area, both to measure intermediate outcomes and inputs. Empirical analyses that exploit the variation induced by the introduction of new interventions seem particularly profitable. In this sense, evaluation studies can be particularly useful as they, at the same time, evaluate the impact of new interventions and can be used to gain a better understanding of the mechanisms that generate these impacts. For the latter objective, however, it is key to use models of individual behavior.

\section{References}

Adair, Linda S. et al. (2009). "Size at Birth, Weight Gain in Infancy and Childhood, and Adult Blood Pressure in 5 Low- and Middle-Income-Country Cohorts: When Does Weight Gain Matter?" American Journal of Clinical Nutrition, 89, 1383-1392.

Almond, Douglas (2006). "Is the 1918 Influenza Pandemic Over? Long Term Effect of In Utero Influenza Exposure in the Post-1940 US Population." Journal of Political Economy, 114, 672712.

Almond, Douglas and Janet Currie (2011a). "Human Capital Development Before Age Five." In Handbook of Labor Economics, Vol. 4b, edited by O. Ashenfelter and D. Card. Elsevier.

Almond, Douglas and Bhashkar Mazumder (2013). "Fetal Origins and Parental Responses." Annual Review of Economics, 5, 1-20.

Almond, Douglas and Janet Currie (2011b). "Killing Me Softly: The Fetal Origins Hypothesis." Journal of Economic Perspectives, 25(3), 153-172.

Amin, Vikesh, Jere R. Behrman, and Hans Peter Kohler (2014). "Schooling has Smaller or Insignificant Effects on Adult Health in the US than Suggested by Cross-Sectional Associations: New Estimates Using Relatively Large Samples of Identical Twins." Social Science and Medicine, 127, 181-189.

Andrew, Alison, Orazio Attanasio, Emla Fitzsimons, and Marta Rubio-Codina (2014). "The (In)Effectiveness of Multiple Micronutrient Powder in Treating and Preventing Childhood Anaemia in Colombia: Analysis, Discussion and Wider Implications of a Randomised Controlled Trial." In progress.

Araujo, Caridad, Orazio Attanasio, Sally Grantham-McGregor, Pablo Muñoz, and Marta RubioCodina (2014). "Comparison of Instruments to Measure Child Development in Children 6 to 42 Months." In progress.

Ashenfelter, Orley and Alan Krueger (1994). "Estimates of the Economic Return to Schooling from a New Sample of Twins.” American Economic Review, 84(5), 1157-1173.

Attanasio, Orazio and Sarah Cattan (2015). "Distorted Beliefs and Parental Investment." In progress.

Attanasio, Orazio, Sarah Cattan, Emla Fitzsimons, Costas Meghir, and Marta Rubio-Codina (2015a). "Estimating the Production Function for Human Capital: Results from a Randomized Control Trial in Colombia." NBER Working Paper No. 20965.

Attanasio, Orazio, Flavio Cunha, and Pamela Jervis (2015b). "The Elicitation and Use of Data on Distorted Beliefs." In progress. 
Attanasio, Orazio, Camila Fernández, Emla Fitzsimons, Sally Grantham-McGregor, Costas Meghir, and Marta Rubio-Codina (2013). "Enriching the Home Environment of Low-Income Families in Colombia: A Strategy to Promote Child Development at Scale." Early Childhood Matters, June.

Attanasio, Orazio, Camila Fernández, Emla Fitzsimons, Sally Grantham-McGregor, Costas Meghir, and Marta Rubio-Codina (2014a). "Using the Infrastructure of a Conditional Cash Transfer Programme to Deliver a Scalable Integrated Early Child Development Programme in Colombia: a Cluster Randomised Controlled Trial." British Medical Journal, 349, g5785.

Attanasio, Orazio, Costas Meghir, and Emily Nix (2014b). "Human Capital Development and Parental Investment in India.” In progress.

Attanasio, Orazio, Costas Meghir, and Ana Santiago (2012). "Education Choices in Mexico: Using a Structural Model and a Randomized Experiment to Evaluate PROGRESA." Review of Economic Studies, 79, 37-66.

Barker, David J. (1995). "Fetal Origins of Coronary Heart Disease." British Medical Journal, 311(6998), 171-174.

Becker, Gary (1964). Human Capital. Columbia University Press (2nd ed. in 1975).

Becker, Gary and Nigel Tomes (1976). "Child Endowments and the Quantity and Quality of Children." Journal of Political Economy, 84, S143-S162.

Becker, Gary S. (1991). A Treatise on the Family. Harvard University Press.

Becker, Gary S. and H. Gregg Lewis (1973). "On the Interaction between the Quantity and Quality of Children: EBSCOhost.” Journal of Political Economy, 81, s279-288.

Becker, Gary S. and Nigel Tomes (1994). "Human Capital and the Rise and Fall of Families." In Human Capital: A Theoretical and Empirical Analysis with Special Reference to Education, 3rd ed. University of Chicago Press, pp. 257-298.

Behrman, Jere and Anil Deolalikar (1990). "Intrahousehold Demand for Nutrients in Rural South India: Individual Estimates, Fixed Effects and Permanent Income." Journal of Human Resources, 25, 665-696.

Behrman, Jere, Robert Pollak, and Paul Taubman (1982). "Parental Preferences and Provision for Progeny." Journal of Political Economy, 102, 52-73.

Behrman, Jere and Mark Rosenzweig (2004a). "Returns to Birth Weight." Review of Economics and Statistics, 86, 586-601.

Behrman, Jere, Mark Rosenzweig, and Paul Taubman (1994a). "Endowments and the Allocation of Schooling in the Family and in the Marriage Market: The Twins Experiment." Journal of Political Economy, 102, 1131-1174.

Behrman, Jere (1988). "Intrahousehold Allocation of Nutrients in Rural India: Are boys favored? Do Parents Exhibit Inequality Aversion?" Oxford Economic Papers, 40, 32-54.

Behrman, Jere R., Maria C. Calderon, Samuel H. Preston, John Hoddinott, Reynaldo Martorell, and Aryeh D. Stein (2009). "Nutritional Supplementation in Girls Influences the Growth of Their Children: Prospective Study in Guatemala." American Journal of Clinical Nutrition, 90, 1372-1379.

Behrman, Jere R. and Mark R. Rosenzweig (2002). "Does Increasing Women's Schooling Raise the Schooling of the Next Generation?" American Economic Review, 92(1), 323-334.

Behrman, Jere R. and Mark R. Rosenzweig (2004b). "Returns to Birthweight." Review of Economics and Statistics, 86, 586-601.

Behrman, Jere R., Mark R. Rosenzweig, and Paul Taubman (1994b). "Endowments and the Allocation of Schooling in the Family and in the Marriage Market: The Twins Experiment." Journal of Political Economy, 102, 1131-1174.

Blakemore, Sarah-Jayne and Kathryn L. Mills (2014). "Is Adolescence a Sensitive Period for Sociocultural Processing?" Annual Review of Psychology, 65, 187-207.

Blundell, Ricchard, Pierre-André Chiappori, and Costas Meghir (2005). "Collective Labor Supply and Children." Journal of Political Economy, 113, 1277-1306.

Browning, Martin and Thomas Crossley (2009). "Are Two Cheap, Noisy Measures Better Than One Expensive, Accurate One?” American Economic Review, 99(2), 99-103. 
Campbell, Frances, Gabriella Conti, James J. Heckman, Seong Hyeok Moon, Rodrigo Pinto, Elizabeth Pungello, and Yi Pan (2014). "Early Childhood Investments Substantially Boost Adult Health." Science, 343(6178), 1478-1485.

Campbell, Frances, Elizabeth P. Pungello, Kirsten Kainz, Margaret Burchinal, Yi Pan, Barbara H. Wasik, Oscar Barbarin, Joseph J. Sparling, and Craig T. Ramey (2012). "Adult Outcomes as a Function of an Early Childhood Educational Program: An Abecedarian Project Follow-Up." Developmental Psychology, 48, 1033.

Campbell, Frances A., Craig T. Ramey, Elizabeth Pungello, Joseph Sparling, and Shari MillerJohnson (2002). "Early Childhood Education: Young Adult Outcomes from the Abecedarian Project." Applied Developmental Science, 6, 42-57.

Caspi, Avshalom, Ahmad R. Hariri, Andrew Holmes, Rudolf Uher, and Terrie E. Moffitt (2010). "Genetic Sensitivity to the Environment: the Case of the Serotonin Transporter Gene and its Implications for Studying Complex Diseases and Traits." American Journal of Psychiatry, 167, 509-527.

Chiappori, Pierre-André, (1988). "Rational Household Labor Supply." Econometrica, 56, 63-90.

Chiappori Pierre-André, (1992). "Collective Labor Supply and Welfare." Journal of Political Economy, 100, 437-467.

Cunha, Flavio, Irma Elo, and Jennifer Culhane (2013). "Eliciting Maternal Beliefs about the Technology of Skill Formation.” NBER Working Paper No. 19144.

Cunha, Flavio and James Heckman (2008). "Formulating, Identifying and Estimating the Technology of Cognitive and Noncognitive Skill Formation." Journal of Human Resources, 43, 738-782.

Cunha, Flavio, James Heckman, Lance Lochner, and Dimitriy Masterov (2006). "Interpreting the Evidence on Life Cycle Skill Formation." In Handbook of the Economics of Education, Vol. 1, edited by Eric A. Hanushek and Finis Welch. Elsevier.

Cunha, Flavio, James Heckman, and Susanne Schennach (2010). "Estimating the Technology of Cognitive and Non-cognitive Skill Formation." Econometrica, 78, 883-931.

Currie, Janet and Rosemary Hyson (1999). "Is the Impact of Shocks Cushioned by Socioeconomic Status? The Case of Low Birth Weight." American Economic Review, 89(2), 245-250.

de Onis, Mercedes, Monika Blössner, and Elaine Borghi (2012). "Prevalence and Trends of Stunting among Pre-school Children, 1990-2020." Public Health Nutrition, 15, 142-148.

Delavande, Adeline (2014). "Probabilistic Expectations in Developing Countries." Annual Review of Economics, 6, 1-20.

Duckworth, Angela L. and Martin E. P. Seligman (2005). "Self-discipline outdoes IQ predicting academic performance in adolescents." Psychological Science, 16, 939-944.

Duflo, Esther, Rema Hanna, and Stephen P. Ryan (2012). "Incentives Work: Getting Teachers to Come to School." American Economic Review, 102(4), 1241-1278.

Duncan, Greg J., Jeanne Brooks-Gunn, and Pamela K. Klebanov (1994). "Economic Deprivation and Early Childhood Development." Child Development, 65, 296-318.

Eckenrode, John et al. (2010). "Long-term Effects of Prenatal and Infancy Nurse Home Visitation on the Life Course of Youths 19-Year Follow-up of a Randomized Trial." Archives of Pediatric and Adolescent Medicine, 164, 9-15.

Engle, Patrice L. et al. and the Global Child Development Steering Group (2011). "Strategies for Reducing Inequalities and Improving Developmental Outcomes for Young Children in LowIncome And Middle-Income Countries." Lancet, 378, 1339-1353.

Fall, Caroline H. D. et al. (2011). "Infant-Feeding Patterns and Cardiovascular Risk Factors in Young Adulthood: Data from Five Cohorts in Low- and Middle-Income Countries." International Journal of Epidemiology, 40, 47-62.

Fernald, Anne, Virginia A. Marchman, and Adriana Weisleder (2013). "SES Differences in Language Processing Skill and Vocabulary are Evident at 18 months." Developmental Science, 16, 234-248.

Fernald, Anne, Renate Zangl, Ana L. Portillo, and Virginia A. Marchman (2008). "Looking While Listening: Using Eye Movements to Monitor Spoken Language Comprehension by Infants and Young Children." In Handbook of the Economics of Education, Vol. 1, edited by I. A. Sekerina, E. M. Fernandez, and H. Clahsen. J. Benjamins Publisher, Amsterdam. 
Fernald, Lia C., Patricia K. Kariger, Melissa Hidrobo, and Paul J. Gertler (2012). "Socio-economic Gradients in Child Development in Very Young Children: Evidence from India, Indonesia, Peru and Senegal." Proceedings of the National Academy of Sciences, 109(suppl.2), 17273-17280.

Fitzsimons, Emla, Bansi Malde, Alice Mesnard, and Marcos Vera-Hernández (2014). "Nutrition, Information, and Household Behavior: Experimental Evidence from Malawi." IFS Working Paper No. $14 / 02$.

Fitzsimons, Emla and Marcos Vera-Hernández (2013). "Food for Thought? Breastfeeding and Child Development." IFS Working Paper No. 13/31.

Ford, Michael, Charles T. Baer, Dongxin Xu, Umit Yapanel, and Sharmi Gray (2009). "The LENA $^{\mathrm{TM}}$ Language Environment Analysis System: Audio Specifications of the DLP-0121." www.lenafoundation.org/TechReport.aspx/Audio_Specifications/LTR-03-2.

Gertler, Paul, James Heckman, Rodrigo Pinto, Arianna Zanolini, Christel Vermeerch, Susan Walker, Susan M. Chang, and Sally Grantham-McGregor (2014). "Labor Market Returns to an Early Childhood Stimulation Intervention in Jamaica." Science, 344, 998-1001.

Grantham-McGregor, Sally, Christine Powell, Susan Walker, and John Himes (1991). "Nutritional Supplementation, Psychosocial Stimulation, and Mental Development of Stunted Children: The Jamaican Study." Lancet, 338, 1-5.

Griliches, Zvi (1979). "Sibling Models and Data in Economics: Beginnings of a Survey." Journal of Political Economy, 87, S37-64.

Hackman, Daniel A., Martha J. Farah, and Michael J. Meaney (2010). "Socioeconomic Status and the Brain: Mechanistic Insights from Human and Animal Research." Nature Reviews Neuroscience, 11, 651-659.

Hamadani, Jena D., Fahmida Tofail, Syef N. Huda, Dewan S. Alam, Deborah A. Ridout, and Orazio Attanasio (2014). "Cognitive Deficit and Poverty in the First 5 Years of Childhood in Bangladesh." Pediatrics, 134, e1001-e1008.

Hanushek, Eric and Dennis Kimko (2000). "Schooling, Labor-Force Quality, and the Growth of Nations." American Economic Review, 90(5), 1184-1208.

Hanushek, Eric and Ludger Woessmann (2008). "The Role of Cognitive Skills in Economic Development." Journal of Economic Literature, 46, 607-668.

Hart, Betty and Todd Risley (1995). Meaningful Differences in the Everyday Experience of Young American Children. Brookes Publishing.

Hazarika, Gautam (2000). "Gender Differences in Children's Nutrition and Access to Health Care." Journal of Development Studies, 37, 73-92.

Heckman, James J. (2012). “An Effective Strategy for Promoting Social Mobility.” Boston Review, September/October.

Heckman, James J., Seong Hyeok Moon, Rodrigo Pinto, Peter A. Savelyev, and Adam Yavitz (2009). "The Rate of Return to the High/Scope Perry Preschool Program." IZA Working Paper No. 4533.

Heckman, James J., Seong Hyeok Moon, Rodrigo Pinto, Peter A. Savelyev, and Adam Yavitz (2010). "Analyzing Social Experiments as Implemented: A Reexamination of the Evidence from the HighScope Perry Preschool Programs." Quantitative Economics, 1, 1-46.

Heckman, James J. (2007). "The Economics, Technology, and Neuroscience of Human Capability Formation." Proceedings of the National Academy of Sciences, 104, 13250-13255.

Heckman, James J. (2008). "The Case for Investing in Disadvantaged Young Children." CESifo DICE Report, 6(2), 3-8. IFO Institute for Economic Research at the University of Munich.

Heckman, James J., Rodrigo Pinto, and Peter A. Savelyev (2013). "Understanding the Mechanisms Through Which an Influential Early Childhood Program Boosted Adult Outcomes." American Economic Review, 103(5), 2052-2086.

Heijmans, Bastiaan T., Elmar W. Tobia, Aryeh D. Stein, Hein Putter, Gerard J. Blau, Ezra S. Susser, P. Eline Slagboom, and L. H. Lumey (2008). "Persistent Epigenetic Differences Associated with Prenatal Exposure to Famine in Humans." Proceedings of the National Academy of Sciences, 105, 17046-17049.

Hoddinott, John, John A. Maluccio, Jere R. Behrman, Rafael Flores, and Reynaldo Martorell (2008). "Effect of a Nutrition Intervention During Early Childhood on Economic Productivity in Guatemalan Adults." Lancet, 371, 411-416. 
Jayachandra, Seema and Rohini Pandi (2015). “Why Are Indian Children So Short?” NBER Working Paper No. 21036.

Jirtle, Randy L. and Michael K. Skinner (2007). "Environmental Epigenomics and Disease Susceptibility." Nature Reviews Genetics, 8, 253-226.

Johnson, Samantha, Neil Marlow, and Dieter Wolke (2004a). "Developmental Assessment of Preterm Infants at 2 Years: Validity of Parent Reports." Developmental Medecine and Child Neurology, $50,58-62$.

Johnson, Samantha, Neil Marlow, Dieter Wolke, Leslie Davidson, Louise Marston, Ann O'Hare, Janet Peacock, and Jane Schulte (2004b). "Validation of a Parent Report Measure of Cognitive Development in Very Preterm Infants." Developmental Medecine and Child Neurology, 46, 389397.

Juster, Thomas (1966a). "Consumer Sensitivity To The Price Of Credit." Journal of Finance, 19, 222-233.

Juster, Thomas (1966b). "Consumers Buying Intentions and Purchase Probability: An Experiment in Survey Design." Journal of the American Statistical Association, 61, 658-696.

Kitzman, H. et al. (2010). "Enduring Effects of Prenatal and Infancy Home Visiting by Nurses on Children." Archives of Pediatric and Adolescent Medicine, 164, 412-418.

Kramer, Michael S. et al. (2001). "Promotion of Breastfeeding Intervention Trial (PROBIT): A Randomized Trial in the Republic of Belarus." Journal of the American Medical Association, 254, 413-420.

Kuzawa, Christopher W. et al. (2012). "Birth Weight, Postnatal Weight Gain, and Adult Body Composition in Five Low and Middle Income Countries." American Journal of Human Biology, 24, 5-13.

Lareau, Annette (2003). Unequal Childhoods: Class, Race, and Family Life. University of California Press.

Lloyd-Fox, Sarah, Marie Papademetriou, Momodou K. Darboe, Nick L. Everdell, Rita Wegmuller, Andrew M. Prentice, Sophie E. Moore, and Claire E. Elwell (2014). "Functional Near Infrared Spectroscopy (fNIRS) to Assess Cognitive Function in Infants in Rural Africa." Nature Scientific Reports, 4, doi:10.1038/srep04740.

Lopez, Humberto and Guillermo Perry (2008). "Inequality in Latin America: Determinants and Consequences." Policy Research Working Paper, World Bank.

Lucas, Robert (1988). "On the Mechanics of Economic Development." Journal of Monetary Economics, 22, 3-42.

Lundeen, Elizabeth A. et al. (2014). "Height-for-Age Z Scores Increase Despite Increasing Height Deficits Among Children in 5 Developing Countries." American Journal of Clinical Nutrition, $100,821-825$.

Maluccio, John A., John Hoddinott, Jere R. Behrman, Reynaldo Martorell, Agnes R. Quisumbing, and Aryeh D. Stein (2009). "The Impact of Improving Nutrition During Early Childhood on Education among Guatemalan Adults." Economic Journal, 119, 734-763.

Manski, Charles (2004). "Measuring Expectations." Econometrica, 72, 1329-76.

Martin, Andrew J. et al. (2012). "Identification of Infants with Major Cognitive Delay Using Parental Report." Developmental Medicine and Child Neurology, 54, 254-259.

Martorell, Reynaldo et al. and Consortium on Health Orientated Research in Transitional Societies Group (2010). "Weight Gain in the First Two Years of Life is an Important Predictor of Schooling Outcomes in Pooled Analyses from Five Birth Cohorts from Low- and Middle-Income Countries." Journal of Nutrition, 140, 348-354.

Grantham-McGregor, Sally, Yin Bun Cheung, Santiago Cueto, Paul Glewwe, Linda Richter, and Barbara Strupp (2007). "Developmental Potential in the First 5 Years for children in Developing Countries." Lancet, 369, 60-70.

Meaney, Michael J. (2010). "Epigenetics and the Biological Definition of Gene? Environment Interactions." Child Development, 81, 41-79.

Mullainathan, Sendil and Ledar Shafir (2013). Scarcity: The New Science of Having Less and How It Defines Our Lives. Allen Lane. 
Murgatroyd, Chris and Dietmar Spengler (2011). "Epigenetics of Early Child Development." Frontiers in Psychiatry, 2, 1-15.

Olds, D. et al. (2007). "Effects of Nurse Home Visiting on Maternal and Child Functioning: Age Nine Follow-Up of a Randomized Trial." Pediatrics, 120, e832-e845.

Olds, D. et al. (2010a). "Home Visiting by Paraprofessionals and by Nurses: A Randomized Controlled Trial." Pediatrics, 110, 486-496.

Olds, David L. (2006). "The Nurse-Family Partnership: An Evidence-Based Preventive Intervention." Infant Mental Health Journal, 27, 5-25.

Olds, D. L. et al. (2010b). "Effects of Home Visits by Paraprofessionals and by Nurses: Age Four Follow-up Results of a Randomized Trial." Pediatrics, 114, 1560-1568.

Owen-Jones, E. et al. (2013). "The Effectiveness and Cost-Effectiveness of the Family Nurse Partnership Home Visiting Programme for First Time Teenage Mothers in England: a Protocol for the Building Blocks Randomised Controlled Trial." BMC Pediatrics, 13, 1-13.

Paxson, Christina and Norbert Schady (2007). "Cognitive Development Among Young Children in Ecuador the Roles of Wealth, Health, and Parenting." Journal of Human Resources, 42, 49-84.

Piketty, Thomas (2014). Capital in the 21st Century. Harvard University Press.

Pitt, Mark M., Mark R. Rosenzweig, and Mohammad Nazmul Hassan (2012). "Human Capital Investment and the Gender Division of Labor in a Brawn-Based Economy." American Economic Review, 102(7), 3531-3560.

Pluess, Michael, Suzanne E. Stevens, and Jay Belsky (2013). "Differential Susceptibility: Developmental and Evolutionary Mechanisms of Gene-Environment Interactions." In The Infant Mind: Origins of the Social Brain, edited by M. Legerstee, D. W. Haley, and M. H. Bornstein. Guilford Press.

Ramey, Craig T., Albert Collier, Joseph Sparling, Frank Loda, Frances Campbell, David Ingram, and Neal Finkelstein (1976). "The Carolina Abecedarian Project: A Longitudinal and Multidisciplinary Approach to the Prevention of Developmental Retardation." In Intervention Strategies for High-Risk Infants and Young Children, edited by T. D. Tjossem. University Park Press, Baltimore, MD, pp. 629-665.

Romer, Paul M. (1990). "Human Capital and Growth: Theory and Evidence." Carnegie-Rochester Conference Series on Public Policy, 32, 251-286.

Rosenzweig, Mark and Kenneth Wolpin (1988). "Heterogeneity, Intrafamily Distribution and Child Health." Journal of Human Resources, 23, 437-461.

Rosenzweig, Mark and Junsen Zhang (2009). "Do Population Control Policies Induce More Human Capital Investment? Twins, Birth Weight and China's One-Child Policy." Review of Economic Studies, 76, 1149-1174.

Rosenzweig, Mark R. and Junsen Zhang (2013). "Economic Growth, Comparative Advantage, and Gender Differences in Schooling Outcomes: Evidence from the Birthweight Differences of Chinese Twins." Journal of Development Economics, 104, 245-260.

Rubio-Codina, Marta, Orazio Attanasio, and Sally Grantham-McGregor (2015). "Mediating Pathways in the Socio-economic Gradient of Child Development: Evidence from Children 6-42 Months in Bogota." IFS Working Paper No. W14/11.

Rubio-Codina, Marta, Orazio P. Attanasio, Costas Meghir, Natalia Varela, and Sally GranthamMcGregor (2014). "The Socio-economic Gradient of Child Development: Cross-Sectional Evidence from Children 6-42 Months in Bogota." Journal of Human Resources, 4, 1001-1008.

Schady, N. et al. (2015). "Wealth Gradients in Early Childhood Cognitive Development in Five Latin American Countries." Journal of Human Resources, 50, 464-483.

Schady, Norbert (2011). "Parents' Education, Mothers' Vocabulary, and Cognitive Development in Early Childhood: Longitudinal Evidence From Ecuador." American Journal of Public Health, 101, 2299-2307.

Schennach, Susanne M. (2004). "Estimation of Nonlinear Models with Measurement Error." Econometrica, 72, 33-75.

Schweinhart, Lawrence J., Jeanne Montie, Zongping Xiang, William S. Barnett, Clive R. Belfield, and Milagros Nores (2005). Lifetime Effects: The High/Scope Perry Preschool Study Through Age 
40. (Monographs of the High/Scope Educational Research Foundation, 14). High/Scope Press, Ypsilanti, MI.

Sparling, Joseph and Isabelle Lewis (1979). Learning Games for the First Three Years: A Guide to Parent-Child Play. University Park Press, Baltimore, MD.

Stein, Aryeh D. et al. (2010). "Growth Patterns in Early Childhood and Final Attained Stature: Data from Five Birth Cohorts from Low- and Middle-Income Countries." American Journal of Human Biology, 22, 353-359.

Thomas, Duncan (1990). "Intra-household Resource Allocation: An Inferential Approach.” Journal of Human Resources, 25, 635-664.

Todd, Petra and Kenneth Wolpin (2006). "Using Experimental Data to Validate a Dynamic Behavioral Model of Child Schooling and Fertility: Assessing the Impact of a School Subsidy Program in Mexico." American Economic Review, 96(5), 1384-1417.

Victora, Cesar G., Linda Adair, Caroline Fall, Pedro C. Hallal, Reynaldo Martorell, Linda Richter, and Harshpal Singh Sachdev (2008). "Maternal and Child Undernutrition: Consequences for Adult Health and Human Capital." Lancet, 371, 340-357.

Walker, Susan P., Susan M. Chang, Christine A. Powell, and Sally M. Grantham-McGregor (2005). "Effects of Early Childhood Psychosocial Stimulation and Nutritional Supplementation on Cognition and Education in Growth-Retarded Jamaican Children: A Prospective Cohort Study." Lancet, 366, 1804-1807.

Walker, Susan P., Susan M. Chang, Christine A. Powell, Emily Simonoff, and Sally M. GranthamMcGregor (2006). "Effects of Psychosocial Stimulation and Dietary Supplementation in Early Childhood on Psychosocial Functioning in Late Adolescence: Follow-Up of Randomized Controlled Trial." British Medical Journal, 333(7566), 472-476.

Walker, Susan P. et al. (2011). "Inequality in Early Childhood: Risk and Protective Factors for Early Child Development." Lancet, 378, 1325-1338.

Weisleder, Adriana and Anne Fernald (2013). "Talking to Children Matters: Early Language Experience Strengthens Processing and Builds Vocabulary." Psychological Science, 24, 21432152.

Willis, Robert J. (1973). "A New Approach to the Economic Theory of Fertility." Journal of Political Economy, 81, S14-64.

Wolfe, Barbara L. and Jere R. Behrman (1984). "Determinants of Women's Health Status and HealthCare Utilization in a Developing Country: A Latent Variable Approach." Review of Economics and Statistics, 66, 696-703.

Yi, Junjian, James J. Heckman, Junsen Zhang, and Gabriella Conti (2015). "Early Health Shocks, Intrahousehold Resource Allocation, and Child Outcomes.” Economic Journal. Forthcoming. 